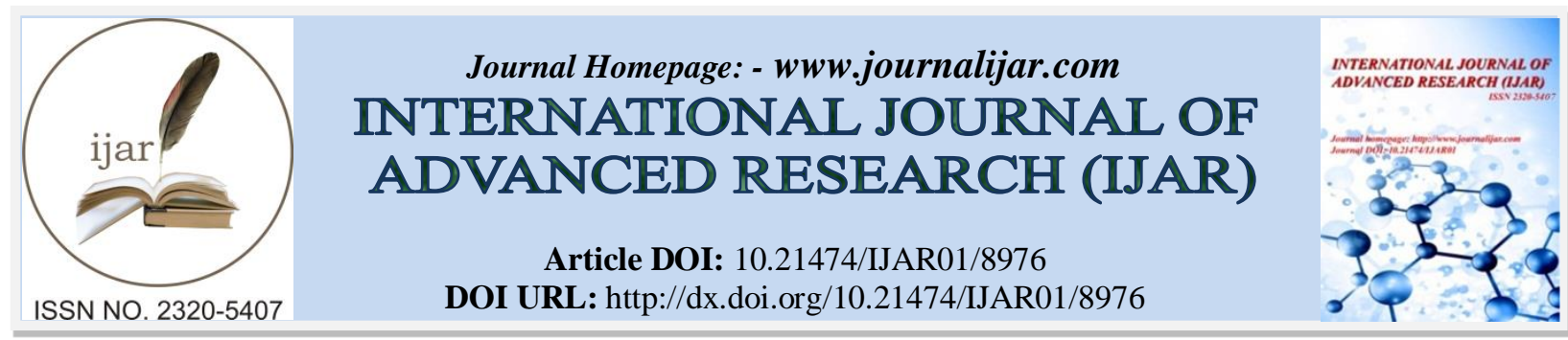

RESEARCH ARTICLE

\title{
THE PREVALENCE OF SMOKING HABITS, EXPOSURE, ATTITUDES, BEHAVIOR AND CURRICULUM TRAINING AMONG THE HEALTHCARE PROFESSION STUDENTS - A CROSS- SECTIONAL STUDY.
}

Dr. Ilayaraja Alagiathiruvevenkadam ${ }^{1}$ and Visallani A/P Kesavan ${ }^{2}$.

1. Department of Physiotherapy, Faculty of Medicine and health sciences, Universiti tunku abdul Rahman, Sungailong, Cheras 43000, Selangor, Malaysia.

2. Alummnus, Department of physiotherapy, Facullty of Therapeutic science, AMU, Cheras, Selangor.

\section{Manuscript Info}

(..........................

Manuscript History

Received: 24 February 2019

Final Accepted: 26 March 2019

Published: April 2019

Key words:-

Chewing Tobacco, Smoking, Healthcare Profession Students, Smoking habits, Exposure, Attitudes, Behaviour, Ccurriculum training.

\section{Abstract}

Background: Healthcare providers have been the major focus for smoking cessation as well as they are in ideal position to educate and advice patients about the negative impact of smoking and serve as behavioural models for the citizens. Therefore, smoking cessation interventions have been shown to be effective when delivered by health profession groups and in increasing the rate of tobacco cessation. The perceptions and attitudes towards the tobacco control by the health profession students determine the capability of delivering the interventions is effective in smoking patients.

Objective: The aim of this study was to determine the prevalence of smoking habits, exposure, attitudes, behaviour and curriculum training among the healthcare profession students in Asia Metropolitan University.

Methods: This was a cross-sectional study carried out among healthcare profession students in Asia Metropolitan University. One hundred and ninety seven participants were selected to participate in the study from four faculties: Faculty of Therapeutic Science, Faculty of Pharmacy, Faculty of Allied Health Science and Foundation in Health Science. Data was collected using self-administered GHPSS questionnaires. Descriptive statistics was used to report the study variables.

Results: A total of 197 participants completed the questionnaire. Prevalence of current smokers was $9.5 \%$. Majority of the participants (86.3\%) had a positive attitude towards smoking cessation intervention. Additionally, only (51\%) indicated that they had received specific training in smoking cessation techniques during the curriculum at the university. The curriculum within the health profession students at the university emphasizes the need for cessation and prevention of smoking.

Conclusion: Healthcare providers have inadequate training towards smoking cessation intervention. Hence, there is an important focus that needs to be highlighted on education modules and smoking cessation training to be incorporated in curriculum preparation. 
Recommendation: There is a crucial part that needs to be focused on addressing the tobacco cessation concerns, by improvising the Health care providers' knowledge, attitudes, practice, and confidence levels in tobacco cessation interventions through implementation of appropriate services for training the health profession students.

Copy Right, IJAR, 2019,. All rights reserved.

\section{BACKGROUND:-}

Healthcare providers have been the important focus for smoking cessation as well as they are in ideal position to educate and advice patients about the negative impact of smoking and serve as behavioural models for the community. Therefore, smoking cessation interventions have been shown to be effective when delivered by health profession groups and in increasing the rate of tobacco cessation.

Furthermore, tobacco use has entered and mobilized the government, corporations and healthcare community for smoking cessation. Many employers and companies have implemented programs to promote smoking cessation among members, and these often include higher insurance rate smokers, education and support programs for quitting, and most recently, a controversial move on the part of some corporations of not hiring tobacco users at all. ${ }^{4}$ Additionally, at local and regional levels, many health organizations have designed and implemented on smoking cessation programmes.

Education is the utmost important in smoking-related health issues and therefore healthcare professionals are in a position to play a vital role in tobacco control by providing counselling and support for their client for successful behaviour and lifestyle changes. Despite in several studies have shown a high prevalence of smokers among health professionals, who do not always set a good example for their patients. ${ }^{5}$

Therefore, health professionals have a unique role to play in prevention and control of tobacco use. Medical students that represent future medical practitioners need to obtain knowledge about smoking related diseases and specific skills necessary for teaching smoking cessation techniques. Failure to address the smoking in clients may be due to the personal smoking behaviours of the health professionals' themselves. ${ }^{6}$

Smoking cessation reduces health risks and improves quality of life and the cumulative risk of dying of cardiovascular and lung diseases can be drastically reduced (up to 90\%) if smokers quit smoking, even late in life. Cessations undertake need to be reinforced by health professionals to achieve long term abstinence. Besides, they act as visible role models and may unintentionally affect the smoking behaviours of others. They are also more likely to maintain attitudes that prevents them from providing patients with anti-smoking advice. ${ }^{7}$

Their own smoking habits may conclude their judgement and influences their ability to adequately counsel smokers. As one can conclude many of their personal smoking behaviours and judgement are formed during their medical education, any successful tobacco control measures within the medical profession will need to begin in advance to graduation from medical school and undergraduate curriculum must include teaching modules and training focusing on role on disease prevention and cessation techniques

The World Health Organization (WHO), the U.S. Centers for Disease Control and Prevention (CDC), and The Canadian Public Health Association (CPHA) have developed the Global Health Professions Student Survey (GHPSS) questionnaire to collect data on tobacco use and cessation counselling among health-profession student in WHO member states. Studies have conducted on the smoking habits of healthcare professionals have found that a disturbingly high percentage of these student's smoke. In a study of Health Professional School Students in Catania University Medical Schools, Italy found that $38.2 \%$ were smokers. ${ }^{8}$ Several studies have indicated that need to improve training in tobacco abuse and techniques for cessation among students of health science. Therefore, the present study was developed to assess the prevalence of smoking habits, exposure, attitudes, behaviour and curriculum training among the healthcare profession students concerning tobacco control and cessation.

In another study conducted in College of Nursing, Bangalore, India revealed that urgent need to include a tobaccocontrol curriculum at undergraduate level. ${ }^{8}$ Furthermore, the study by Ficarra et al (2011) found there is high 
prevalence of smokers among hospital personnel than in the general population with the current smokers were $44 \%$ and ex-smokers were $18.5 \%{ }^{9}$

The findings of these researchers' studies point to the importance of the attitudes, knowledge and beliefs among the health professional's students about smoking and providing smoking cessation interventions and programs so that they can enter their field as non-smoker, equipped with the knowledge required to assist their client in changing their lifestyle in smoking behaviours.

At Asia Metropolitan University, the health students receive information about the risk factors and the ill effects of the smoking throughout their duration of their education, with discussions of the issue starting from the assessment and going more in depth with pathophysiology, where smoking is the main contributors for the disease processes and eventually continued to be addressed in their prescription of the medicines, interventions, counselling courses since it has been included with the faculty of pharmacy, faculty of therapeutic sciences and faculty of allied health sciences students.

With the knowledge and information provided through the course of education, the percentage of smoke in Asia Metropolitan University healthcare students should be lower due to increased awareness from the negative consequences of tobacco use. Therefore, the purpose of this study is to discover the prevalence of smoking in the health professional students at Asia Metropolitan University.

This study will investigate the smoking behaviours, attitudes towards smoking and smoking cessation, and the exposure, behaviour and curriculum training towards the role of health professionals in patient smoking cessation.

\section{METHODS AND PROCEDURE: -}

The Study design is a cross-sectional study, based on the Simple random sampling method the data was collected. Totally 197 subjects were analyzed. The study was conducted in Asia Metropolitan University, with a total duration of 11 months. The inclusion criteria were selected as per the students who erolled in healthcare courses at the Asia Metropolitan University from the year and also who are willing to participate were included. Other than healthcare professional students in Asia Metropolitan University (undergraduate and postgraduate management studies) and who were not willing to participate were excluded.

Questionnaire are used as Independent Variable whereas the prevalence of smoking habits, exposure, attitudes, behavior and curriculum training among the healthcare profession students in Asia Metropolitan University were dependent variables.

Measuring the prevalence of smoking habits, exposure, attitudes, behaviour and curriculum training among the healthcare profession students in Asia Metropolitan University by using the Modified GHPSS (Global Health Profession Students Survey) were the out come measures.

- Modified Global Health Profession Student Survey (GHPSS) questionnaire

The questionnaire is composed of 42 questions and distributed in 6 sections

* Demographics (i.e. age, gender, course year)

(Questions 1-3)

* Prevalence of tobacco use (Questions 4-9)

* Exposure to environmental tobacco use (i.e. time spent with people who smoke in places other than home) (Questions 11-12)

* Attitudes (i.e. opinions about no-smoking policies and laws, and about the role of healthcare professionals in smoking cessation)

(Questions 12-22)

- Behaviour/ cessation (i.e. smoking habit, willingness to stop, opinions about healthcare professionals who used to smoke)

(Questions 23-28)

* Curriculum/training (i.e. formal training in smoking cessation techniques on the medical curriculum and knowledge about the methods-pharmacological or counselling techniques-for help to quit)

(Questions 29-35)

Microsoft excel 2010 as uses as statistical tool. 


\section{A. 3.11 Study Methodology Design}

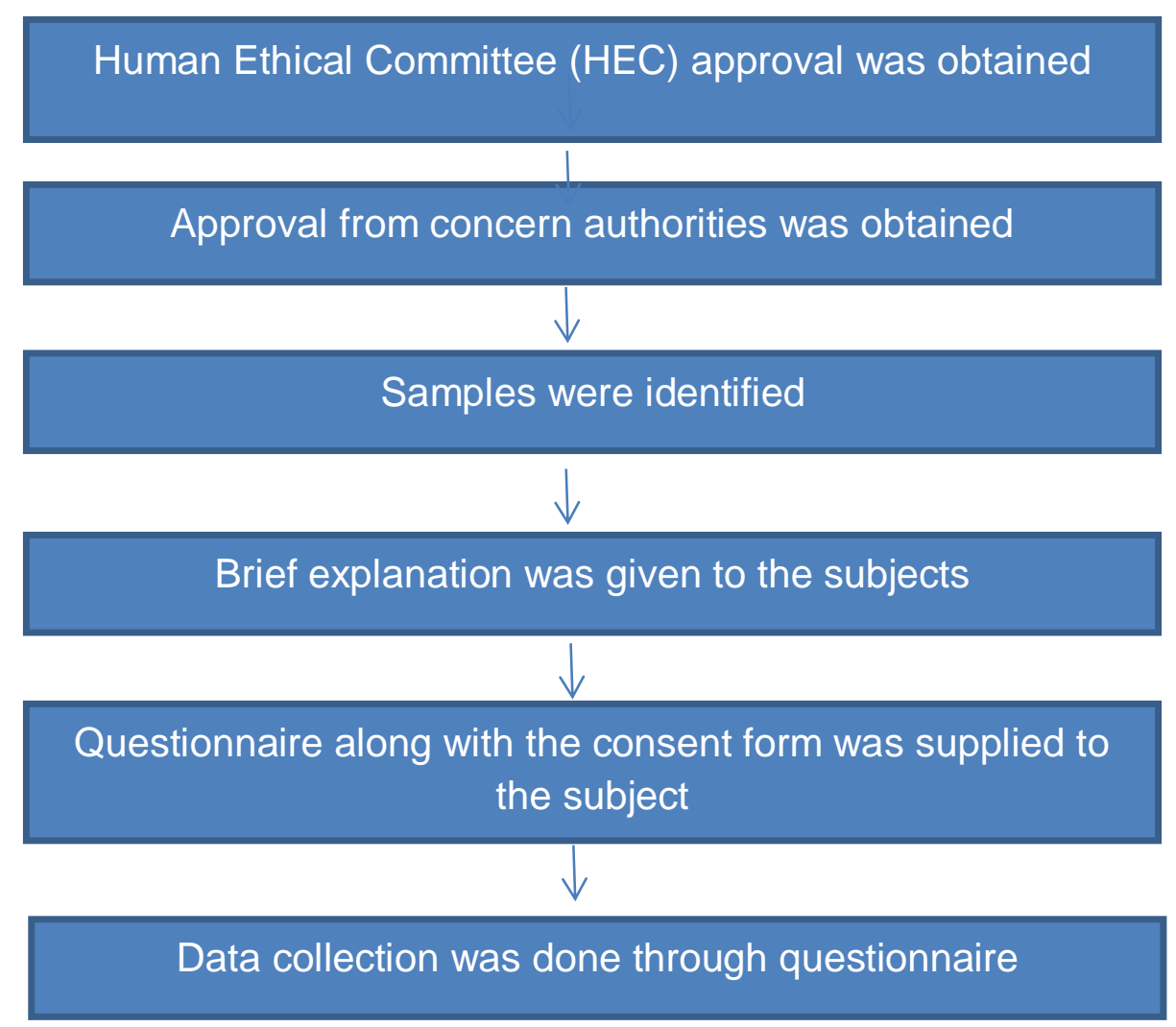

\section{Data was analysed}

\section{B. 3.12 PROCEDURE}

This study utilized a descriptive cross-sectional survey design to determine the prevalence of smoking habits, exposure, attitudes, behaviour and curriculum training among the healthcare profession students in Asia Metropolitan University.

Through the analysis of the information, the study sought to show that the rates of smoking among health profession students were lower than that of non-smokers. Health profession students of all educational levels at the university were invited to participate in the study by completion of a questionnaire.

The instrument chosen for this study was the Modified Global Health Professions Student Survey (GHPSS), which was developed by the World Health Organizations, the Centers for Disease Control and Prevention, and the Canadian Public Health Association in 2005. A total of 35 questions is composed in this questionnaire and distributed in 6 sections. This survey collects data on participant demographics, tobacco use prevalence, exposure to environmental tobacco smoke, attitudes about tobacco use, behaviour/cessation, and whether the participants had received training on the dangers of smoking and in cessation interventions through their university (Centers for Disease Control and Prevention, n.d.).

The measurement reliability is high, with an alpha of .815 (Gualano, Saulle, La Torre\& Bontempi). This questionnaire has been administered many times to different types of health profession's students, and the result of those studies inform current knowledge of the global behaviours and attitudes towards tobacco use of student health 
professionals. The survey was adapted for this study through the inclusion of additional questions expanded the potential age-ranges choice and the range of number of years in school.

The population of interest was health professions students at all level of education, and the sample consisted of current students at Asia Metropolitan University, including the Faculty of Therapeutic Science, Faculty of Pharmacy, Foundation in Health Science, Faculty of Allied Health Science. After ethical committee approval and concern authorities of Asia Metropolitan University, the samples were identified and brief explanation is given for each participants and consent form along with the questionnaire is supplied to the participants. A total of 197 participants included in this study. The individual responses were kept confidential and the collected data from the survey was analysed using descriptive analysis in Microsoft Excel 2010. Of the data collected, selected portions were put into graphs to better analyse and visualize the results.

\section{DATA ANALYSIS AND INTERPRETATION}

In the data analysis part, descriptive statistics were used. Descriptive statistic is used to describe the population parameters and the sample statistics. The study, (mean \pm SD) is used to analyse the demographic data and the frequency in the form of percentages is calculated for each questions.

Table 1

\begin{tabular}{|l|c|c|}
\hline Socio-demographic variable & N & Mean \pm SD \\
\hline Age & & \\
14 years > & 15 & \\
15 to 18 years & 130 & $65.6 \pm 58.7$ \\
19 to 24 years & 52 & \\
25 to 29 years & & $98.5 \pm 70.0$ \\
30 years or older & 148 & \\
\hline Gender & 49 & $49.3 \pm 43.9$ \\
Female & 16 & \\
Male & 18 & \\
Course & 53 & \\
First year & 110 & \\
Second year & & \\
Third year & & \\
Fourth year & & \\
Fifth year & & \\
Sixth year & & \\
Seventh year & & \\
\hline
\end{tabular}

From the Table 1, shows that (mean \pm SD) for the demographic data are Age (65.6 \pm 58.7$)$, Gender $(98.5 \pm 70.0)$, Course $(49.3 \pm 43.9)$ respectively.

Table 2

\begin{tabular}{|l|c|c|}
\hline Prevalence & Yes (\%) & No (\%) \\
\hline Tried or experimented before & $33 \%$ & $67 \%$ \\
\hline Smoked on school premises & $9 \%$ & $91 \%$ \\
\hline Smoked in school buildings & $8 \%$ & $92 \%$ \\
\hline Used chewing tobacco and etc & $3 \%$ & $97 \%$ \\
\hline Used chewing tobacco and etc in school premises & $2 \%$ & $98 \%$ \\
\hline Used chewing tobacco and etc in school buildings & $2 \%$ & $98 \%$ \\
\hline Percentages & $\mathbf{9 . 5 \%}$ & $\mathbf{9 0 . 5 \%}$ \\
\hline
\end{tabular}

Table 3

\begin{tabular}{|l|c|c|}
\hline Exposure & Yes (\%) & No (\%) \\
\hline School have official policy banning smoking & $71 \%$ & $29 \%$ \\
\hline Smoking ban for school buildings and clinics enforced & $67 \%$ & $33 \%$ \\
\hline Percentages & $\mathbf{6 9 \%}$ & $\mathbf{3 1 \%}$ \\
\hline
\end{tabular}


Table 4

\begin{tabular}{|c|c|c|}
\hline Attitudes & Yes $(\%)$ & No $(\%)$ \\
\hline Ban tobacco sales to adolescents & $81 \%$ & $19 \%$ \\
\hline Complete ban of tobacco product advertisement & $89 \%$ & $11 \%$ \\
\hline Smoking banned in restaurants & $91 \%$ & $9 \%$ \\
\hline Smoking banned in discos/bars/pubs & $56 \%$ & $44 \%$ \\
\hline Smoking banned in enclosed public places & $82 \%$ & $18 \%$ \\
\hline Get training on cessation techniques & $88 \%$ & $12 \%$ \\
\hline As "role models" for their patients & $86 \%$ & $14 \%$ \\
\hline Routinely advise their patients to quit smoking & $97 \%$ & $3 \%$ \\
\hline Routinely advise to quit tobacco products & $96 \%$ & $4 \%$ \\
\hline Role in giving advice and information on smoking cessation & $98 \%$ & $2 \%$ \\
\hline Chances of quit smoking increased if health professionals advise & $86 \%$ & $14 \%$ \\
\hline Percentages & $86.3 \%$ & $13.6 \%$ \\
\hline
\end{tabular}

Table 5

\begin{tabular}{|c|c|c|}
\hline Behaviour/Cessation & Yes $(\%)$ & No $(\%)$ \\
\hline Want to stop smoking now & $89 \%$ & $11 \%$ \\
\hline Ever tried to stop smoking & $72 \%$ & $28 \%$ \\
\hline Ever received help or advice to stop smoking & $69 \%$ & $31 \%$ \\
\hline Want to stop using tobacco products & $87 \%$ & $13 \%$ \\
\hline Health professionals who smoke less likely to advise patients & $80 \%$ & $20 \%$ \\
\hline Health professionals who use tobacco products less likely to advise patients & $77 \%$ & $23 \%$ \\
\hline Percentages & $79 \%$ & $21 \%$ \\
\hline
\end{tabular}

Table 6

\begin{tabular}{|c|c|c|}
\hline Curriculum/Training & Yes $(\%)$ & No $(\%)$ \\
\hline Taught in classes about danger of smoking & $93 \%$ & $7 \%$ \\
\hline Discussion on why people smoke during school training & $86 \%$ & $14 \%$ \\
\hline Learn on important to record tobacco history & $84 \%$ & $16 \%$ \\
\hline Received formal training in smoking cessation & $51 \%$ & $49 \%$ \\
\hline Learn on important to provide educational materials & $87 \%$ & $13 \%$ \\
\hline Heard of nicotine replacement therapies in tobacco cessation & $74 \%$ & $26 \%$ \\
\hline $\begin{array}{l}\text { Heard of using antidepressant in tobacco } \\
\text { cessation }\end{array}$ & $48 \%$ & $52 \%$ \\
\hline Total Percentages & $\mathbf{7 4 . 7 1 \%}$ & $25.28 \%$ \\
\hline
\end{tabular}

\section{RESULT:-}

The questionnaire was administered to 197 students including in all health profession students. Within the individual programs the response rates taken from the Faculty of Therapeutic Science, Faculty of Allied Health Science, Faculty of Pharmacy and Foundation of Health Sciences.

\section{Demographics}

In the demographics questions asked the participants his or her age, gender, and current year. Based on the result from their age, $8 \%$ of the respondents were in the range from 15 to 18 years old, $66 \%$ were in the range from 19 to 24 years old, and $26 \%$ were in the age range from 25 to 29 years old. The participants were asked their gender, and $75 \%$ were females while $25 \%$ responded that they were male. They were also asked to identify their current course year in school and the results were as follows: $8 \%$ were in the first year, $9 \%$ were in the second year, $27 \%$ were in the third year, and $56 \%$ reported having been in school for 4 years. The number of female participants was higher than that of males in all first, second, third and fourth years. 


\section{Smoking Prevalence}

The prevalence of smoking in the health profession students at the university was determined in the first section of the questionnaire. This study has shown that the prevalence of tobacco use among health profession students in Asia Metropolitan University is $9.5 \%$.

\section{Exposure to Environmental Tobacco Smoke}

In this study, the participants were investigated on the exposure to environmental tobacco smoke. This study has shown that the exposure to environmental tobacco smoke is $69 \%$.

\section{Attitudes}

Attitudes towards smoking were assessed through the series of questions. Based on the responses, the result for the attitude of health profession students towards tobacco cessation was $86.3 \%$.

\section{Behaviour/Cessation}

Behaviour or Cessation towards the tobacco smoke was assessed and the result was $79 \%$.

\section{Curriculum/ Training}

Some questions addressed the smoking education and training cessation that health profession students had received in University. This study has shown that total percentage for the curriculum/ training towards the tobacco cessation received by the health profession students were $74.71 \%$.

\section{Discussion: -}

\section{Smoking Prevalence}

The participants were asked if they had ever tried or experimented with cigarette smoking, even one or two puffs. $33 \%$ of the participants responded that they had tried or experimented with cigarette smoking, while $67 \%$ of the participants responded that they had not. The students were also asked whether they have used chewing tobacco, snuff, bidis, cigars or pipes, $3 \%$ of the participants stated they had and $97 \%$ stated they had not.

\section{Exposure to Environmental Tobacco Smoke}

The participants were asked if their school have an official policy banning smoking in school buildings and clinics. $71 \%$ of the participants responded that their school have an official policy banning smoking and $29 \%$ responded that their school did not have an official policy banning. The participants were also asked is the school's official smoking ban for school buildings and clinics enforced, $67 \%$ participants stated that their school's official smoking ban were enforced and 33\% participants stated were not enforced.

\section{Attitudes}

Based to the responses, $81 \%$ of the participants were responded that sales tobacco products to adolescent under 18 should be banned and $89 \%$ of the participants' belief that advertising of tobacco products should be completely banned. The participants were also asked about the banning of smoking in various public places and the result as follows: in restaurants- $91 \%$, in discos/bars/pubs $-56 \%$, enclosed public places- $82 \%$. This specifies that the greater part of the respondent stated and agree with bans or hinder on smoking in public areas. The result showed $88 \%$ of the respondent belief that health professionals should get specific training on cessation techniques. The responses indicate that $86 \%$ of the participants' belief that health professionals serve as role model for their patients and the publics. $86 \%$ of the participants stated that cessation interventions increased if a health professional advises their patients to quit. When asked about the role in giving advice or information about smoking cessation to patients, $98 \%$ of the participants agreed. The responses indicate recognition in the role of the health professionals has on the chance of success in tobacco cessation attempt of their patients.

\section{Behaviour/Cessation}

When asked if they had tried to stop smoking now, $89 \%$ of the participants responded they do want to quit and $11 \%$ responded that they do not want to quit. The next question asked if they have received any help or advice to help to stop smoking, 69\% responded that they had received and 31\% responded that they had not. When asked about the health professionals who smoke less likely to advise patients to stop smoking, the results were $80 \%$ agreed and $20 \%$ had not agreed. The responses were that $77 \%$ agreed and $23 \%$ had not agreed that health professionals who use other tobacco products less likely to advise patients to stop smoking. 


\section{Curriculum/ Training}

When asked if they had received any training in school about the dangers of smoking, 93\% indicated that they had. The participants were asked if they had ever discussed in the classes the reasons why people smoke, $86 \%$ indicated that they had. Participants also were asked if they had learned during their school training about the importance of recording tobacco use history as part of a patient's general medical history, and $84 \%$ indicated that they had learned. When asked if they had ever received any formal training in smoking cessation approaches to use with patients, $51 \%$ indicated that they had. The participants were asked if they had learned in school that it is important to provide educational materials to support smoking cessation to patients who want to quit smoking, $87 \%$ responded that they had learned. When asked on the knowledge of nicotine replacement therapies (i.e. patches or gum) in tobacco cessation programs, and 74\% indicated that they had heard, and when asked on the knowledge of antidepressants in tobacco cessation programs (i.e. bupropion or Zyban), indicated that only $48 \%$ only had heard of the use of antidepressant in tobacco cessation programs. In conclusion, the results indicate that health profession students need further training and education in tobacco cessation programme which would contribute to more successful cessation intervention.

The major objectives of this cross-sectional study were to examine the prevalence of smoking habits among the Healthcare Profession students and their attitudes, knowledge and beliefs about tobacco cessation training. The findings from this survey are interesting and have found important results which are worth to discuss. Hence, findings of the present study may be compared with other studies conducted elsewhere in the world. Our study revealed healthcare profession students hold good knowledge and positive attitudes towards tobacco control and cessation. However, their training related to the tobacco control and cessation was limited.

It shows that smoking is still an issue for some health profession students, as $9.5 \%$ reported current cigarette smoking. However, that percentage is substantially lower than that of people who do not currently smoke. This result compares favourably to other studies that have utilized the GHPSS, and which show a wide range of results in regards of current smoking status in students. Results from a 2013 survey of health professional school students in Italy showed that $38.2 \%$ currently smoked. Besides, the results of the GHPSS conducted by the WHO from 2005 to 2009 showed current smoking in nurses ranged from less than 5\% to 43.9\%, depending on the country surveyed, and over half of the country surveyed, over $20 \%$ of the students' smoked. ${ }^{11}$

When the GHPSS was conducted in 2010 on students in Malta, it showed that $27.1 \%$ were current smokers. A 2009 GHPSS survey of students in Spain (University of Balearic Islands) showed that $26.1 \%$ of the nursing and physiotherapy students surveyed currently smoked. ${ }^{12}$ The results from these studies show that the current smoking rates reported by the health profession students and Asia Metropolitan University in this study fall on the lower end range of percentages of current smokers, and when compared with the other studies, show an expected or normal percentage of currently smoking students.

Interestingly, another area that the GHPSS explored is that knowledge toward smoking and smoking cessation has an important effect on assessing smoking status, giving advice to the patients, and the provision or referral for smoking cessation treatment by health professionals. In the present study observed, "banning tobacco sales to adolescents" (81\%)," ban of advertising of tobacco products" (89\%)," ban smoking in restaurants" (91\%), and "ban smoking in enclosed public places" (82\%). In this study, indicates that health profession students have adequate knowledge and attitudes about tobacco-related issues. These results were almost similar to the studies conducted among dental professionals from India. ${ }^{13}$

Another finding of this study is that $51 \%$ of the participants reported receiving formal training in smoking cessation approaches to use with patients, and this compares favourably with the other surveys. The original GHPSS conducted by the WHO found that majority of the students received little or no formal training in tobacco cessation techniques and approaches as a part of their curriculum and training. ${ }^{11}$ This lack of training was a compatible result throughout many other studies, with only $21.3 \%$ of students in Catania received ${ }^{7}, 12.6 \%$ of students in Malta reported received training ${ }^{12}$ and $6.7 \%$ of the nursing students in Mauritus received formal training. ${ }^{15}$ In contrary, $80 \%$ of the participants have reported that they have received formal training on dangers of smoking and importance of asking their patients about smoking habits. ${ }^{8}$ This shows that present study is at the lower level when compared.

Factor that influences the differences in the result might be that different levels of education because in this study majority is taken from the third year (27\%) and fourth year $(56 \%)$ health profession students. However, health professionals have a crucial role to play in prevention and control of tobacco use, therefore, it is clear that health 
profession students' education in tobacco cessation techniques is an important area to be focused on and also with the correction of lack of training. Universities should include formal tobacco cessation training in the curriculum for their health profession students.

Another finding of this study is more than half of the medical student's belief that health professionals have an important role and served to be a role model in cessation of smoking by giving advice or information to their patients, it is salient because the future health practitioner have a higher influential in tobacco cessation by providing smoking prevention counselling and programmes. This study found that more than $90 \%$ of the participants supported that health professionals have a role in smoking cessation for their patients, but only $86 \%$ believe that a patient's chances of quit smoking are increased if a health professional advises him or her to quit.

Moreover, $86 \%$ of the participants believed that health professionals should be a "role models" for their patients, but only $77 \%$ believe that a health professional would be less likely to advise patients to stop smoking if the health professionals use tobacco products and $80 \%$ believe if the health professionals smoke. In many other studies have reported that most of the students in the health professions believe that health professionals have a role in the successful tobacco cessation but in contrary there are difficulty in students' comprehension on the effects of successful tobacco cessation on their patients which would be caused by their own personal smoking behaviours, that lower percentage of the participants responded that they believe health professionals who smoke less likely to advise patients to cease smoking. ${ }^{7,11,12}$ Assuming, in the future, specific training on tobacco cessation was included in the curriculum of the students', emphasis on the changes in the students' attitudes need to be explored whether there were a change on the attitudes towards the role of health professions in tobacco cessation.

In this study, the GHPSS also have discovered that $89 \%$ of the health profession students would want to stop smoking and also found out that $72 \%$ have tried to stop smoking cigarettes. Besides, only $69 \%$ of the participants have responded that they have received help or advice for them to stop smoking cigarettes. These findings show that a positive outcome can be seen in future on the health profession students in tobacco cessation and would have a favourable outcome in the effects on the personal smoking behaviour in advising patients to stop smoking.

To be explored in a different direction, the use of battery-powered electronic cigarettes is growing around the world and it is highly competitive in the market. The GHPSS has developed in the year 2005, before the rise of the ecigarettes and also this type of nicotine use was not included on the instrument. Smoking electronic cigarettes or "vaping" is an expanding rage for many. ${ }^{16}$ Some people believe that using an electronic cigarette as a substitute for tobacco smoking either with an intention of tobacco cessation or with no intention of quitting. ${ }^{16}$ Therefore, the prevalence of vaping among the health profession students is a sector for future exploration.

This study of the health profession students at Asia Metropolitan University is pertinent and convenient, the increasing urgency in prevention and cessation of the tobacco smoking should be well reviewed, and clearly understood that health professionals play an important role in successful tobacco cessation for their patients. Besides, it also has revealed that formal training on their curriculum on smoking cessation would show the comparison in the smoking habits and attitudes towards smoking and continued need for training is mandatory to improve the responsibilities in tobacco cessation for their patients.

\section{Conclusions: -}

Most of the health professions students attained good knowledge scores while less than half of the health profession students surveyed had an average level of knowledge on tobacco cessation interventions. Besides, most of the health profession students had a positive attitude and behaviours on smoking cessation interventions. The implication of this study that is important to put into practice the educational programmes in Health Profession University on how to deal with the patients with smoking habits and provides interventions on tobacco cessation.

A lower prevalence of smoking among the Health Profession student's community and together with a better knowledge towards the tobacco issues, would increase professionalism standards and eventually would lead to greater improvement in health. The major areas of inadequate training were reasons for smoking, hence urgent need in curriculum preparation is mandatory to develop an effective health professional at communities. Education and training on tobacco cessation should be continued to improve the cessation rates. 


\section{Demographic details}

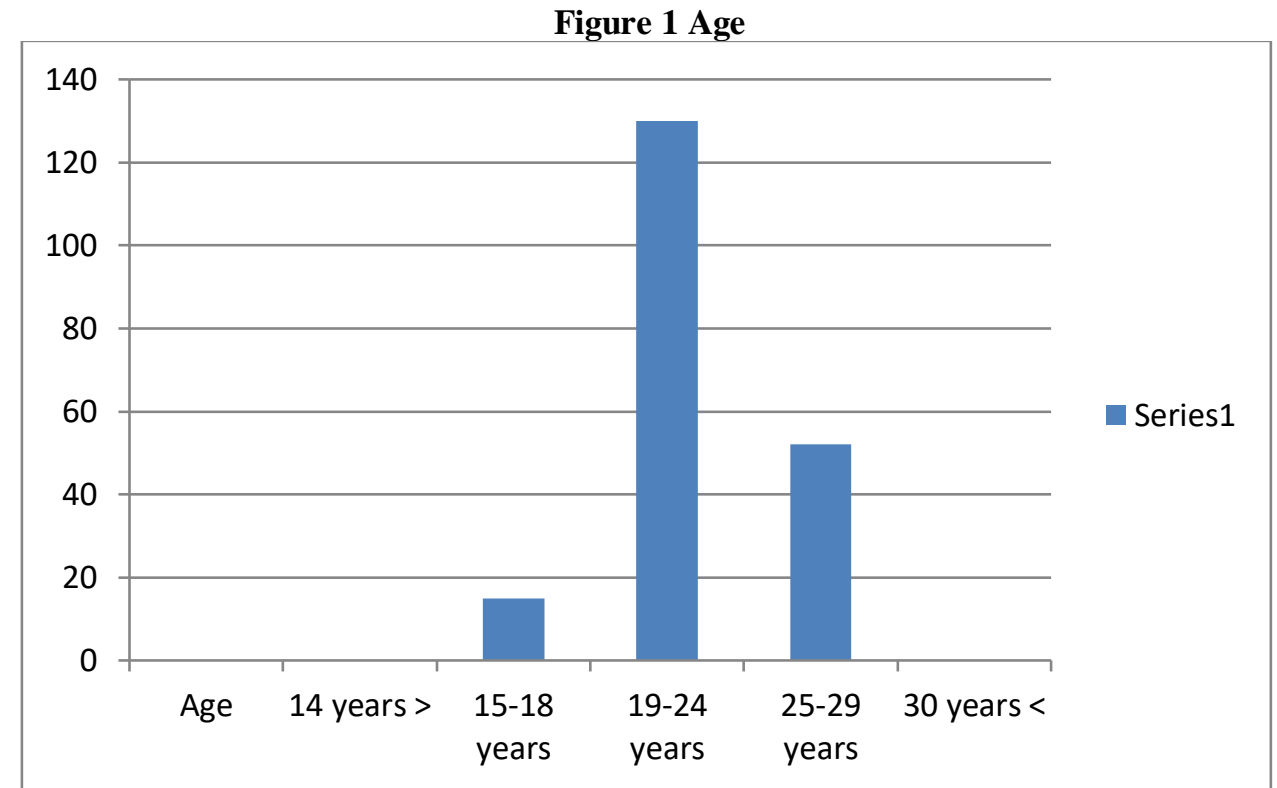

Figure 2 Gender

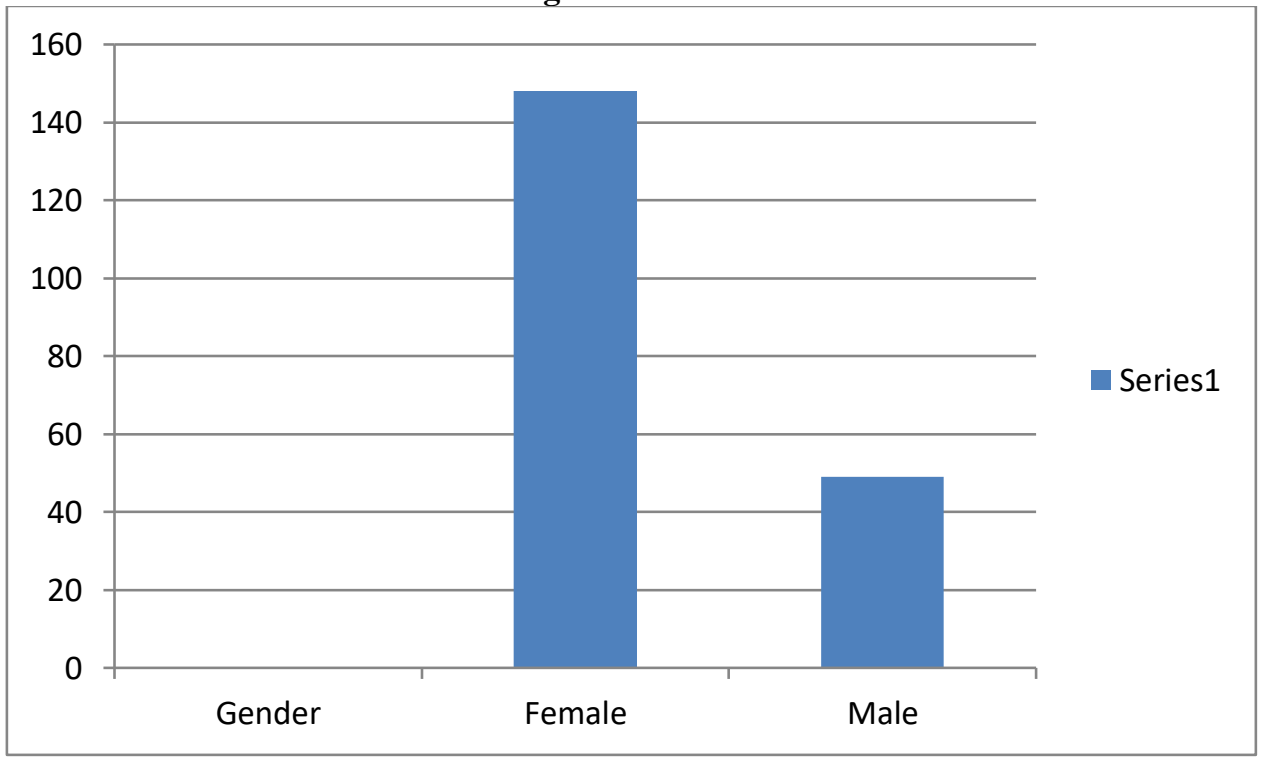


Figure 3 Course

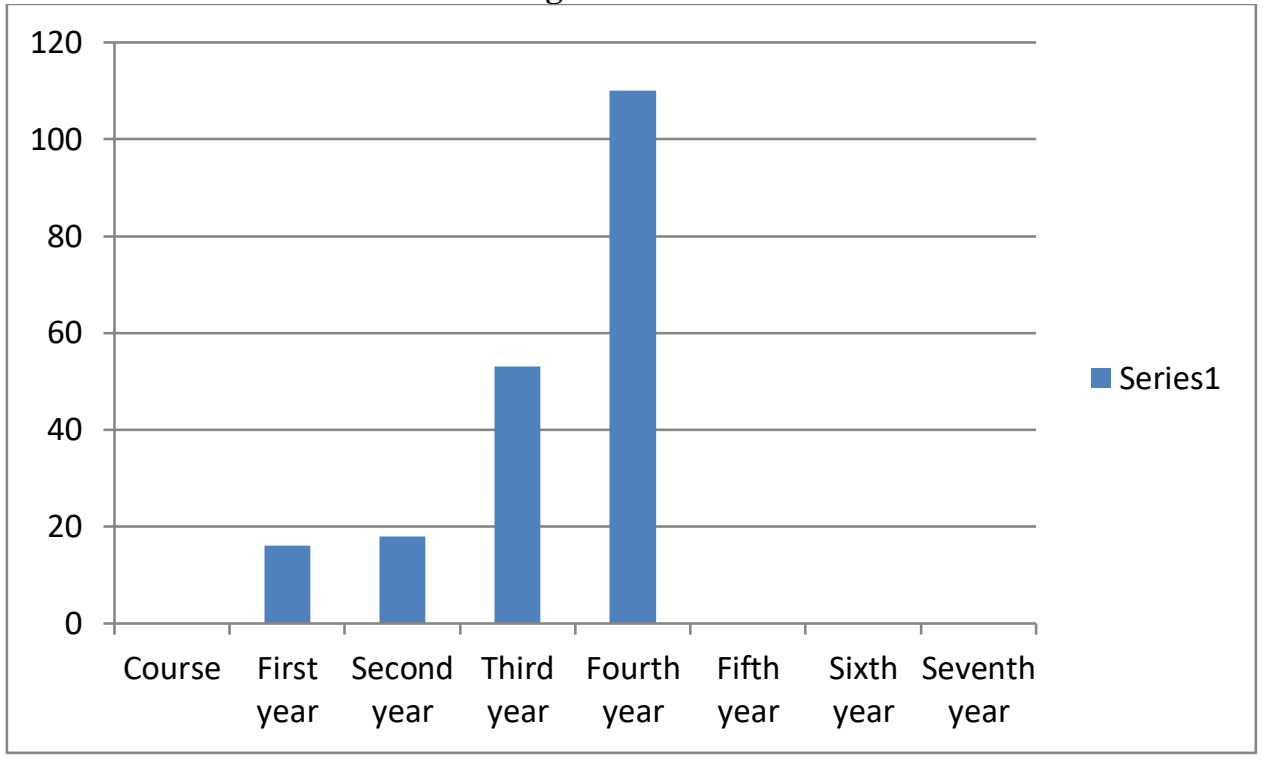

Figure 4 Age

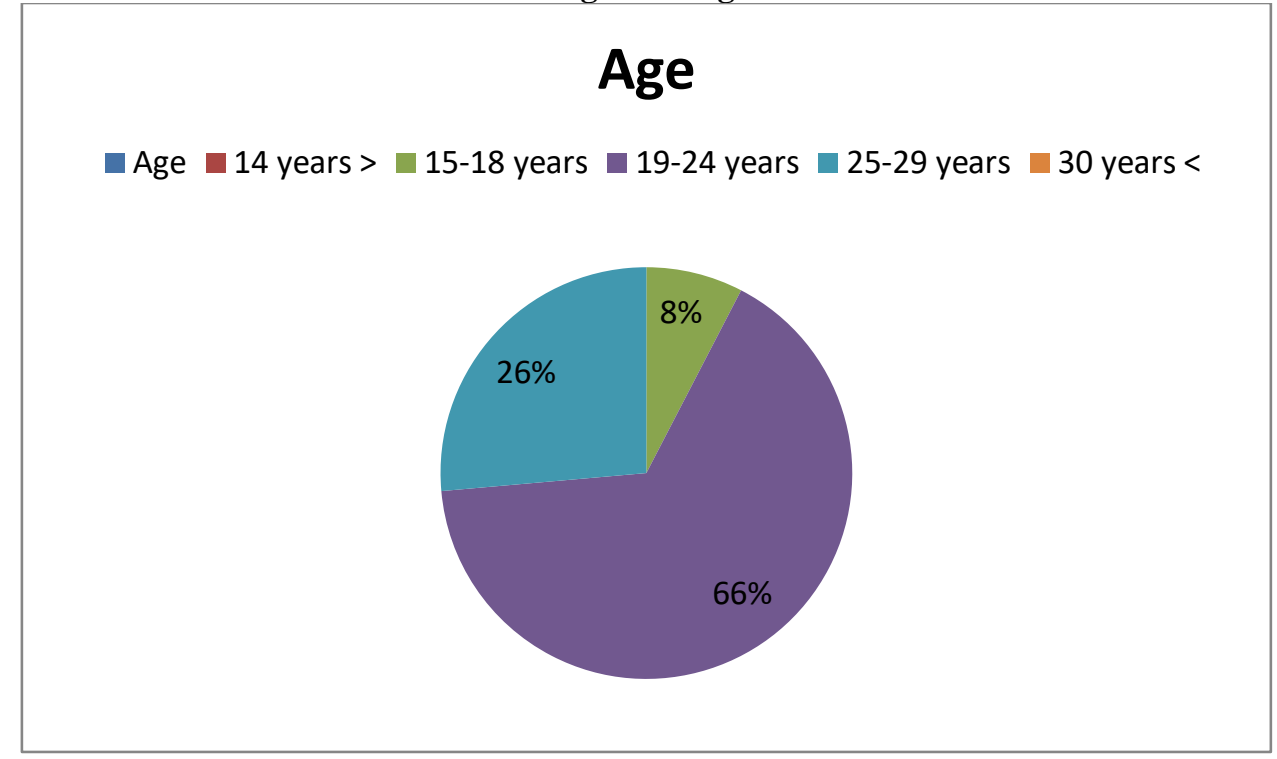


Figure 5 Gender

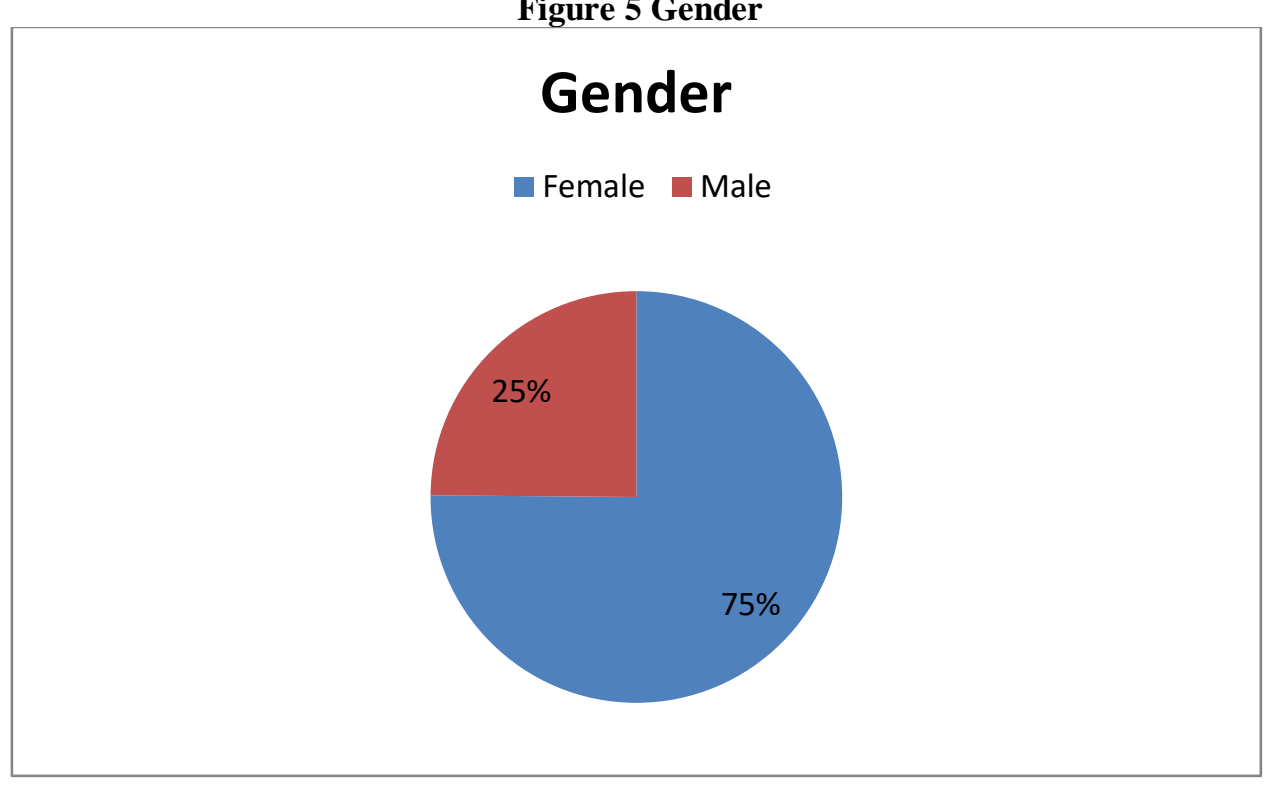

Figure 6 Course

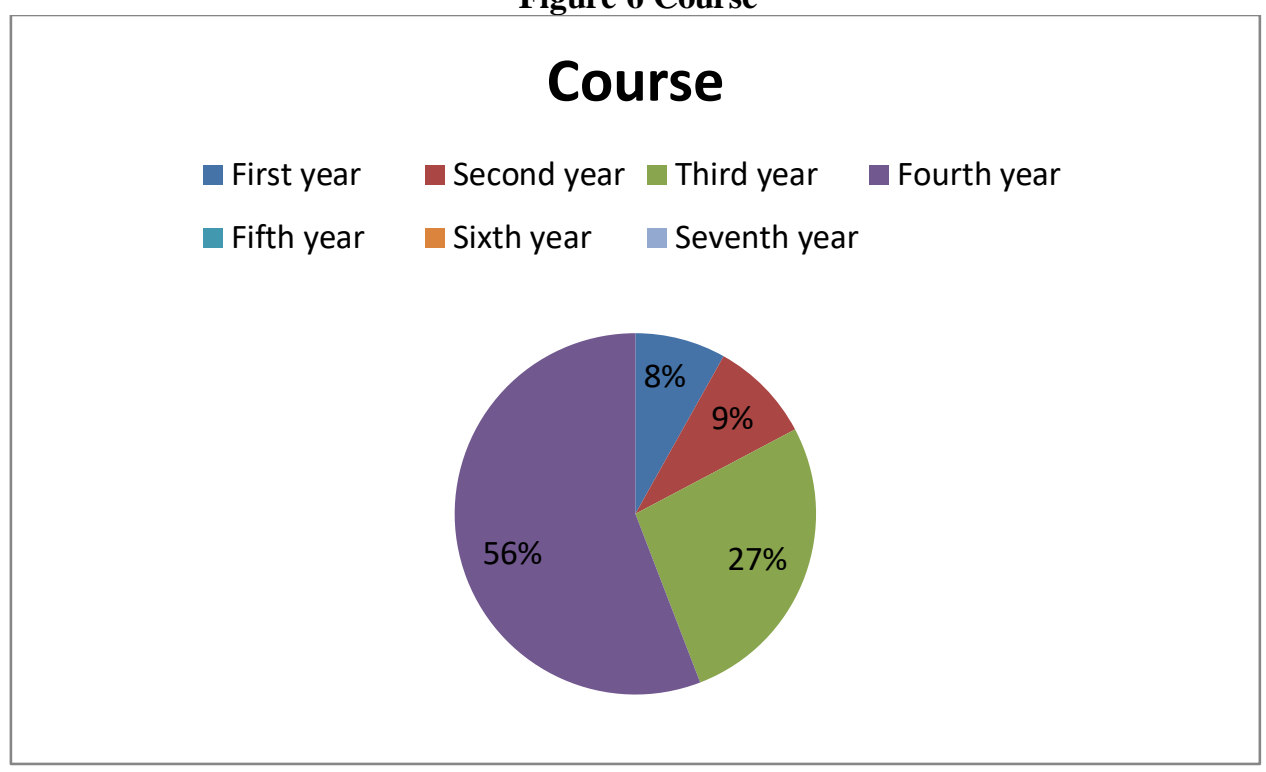




\section{Prevalence}

Figure 7 Prevalence

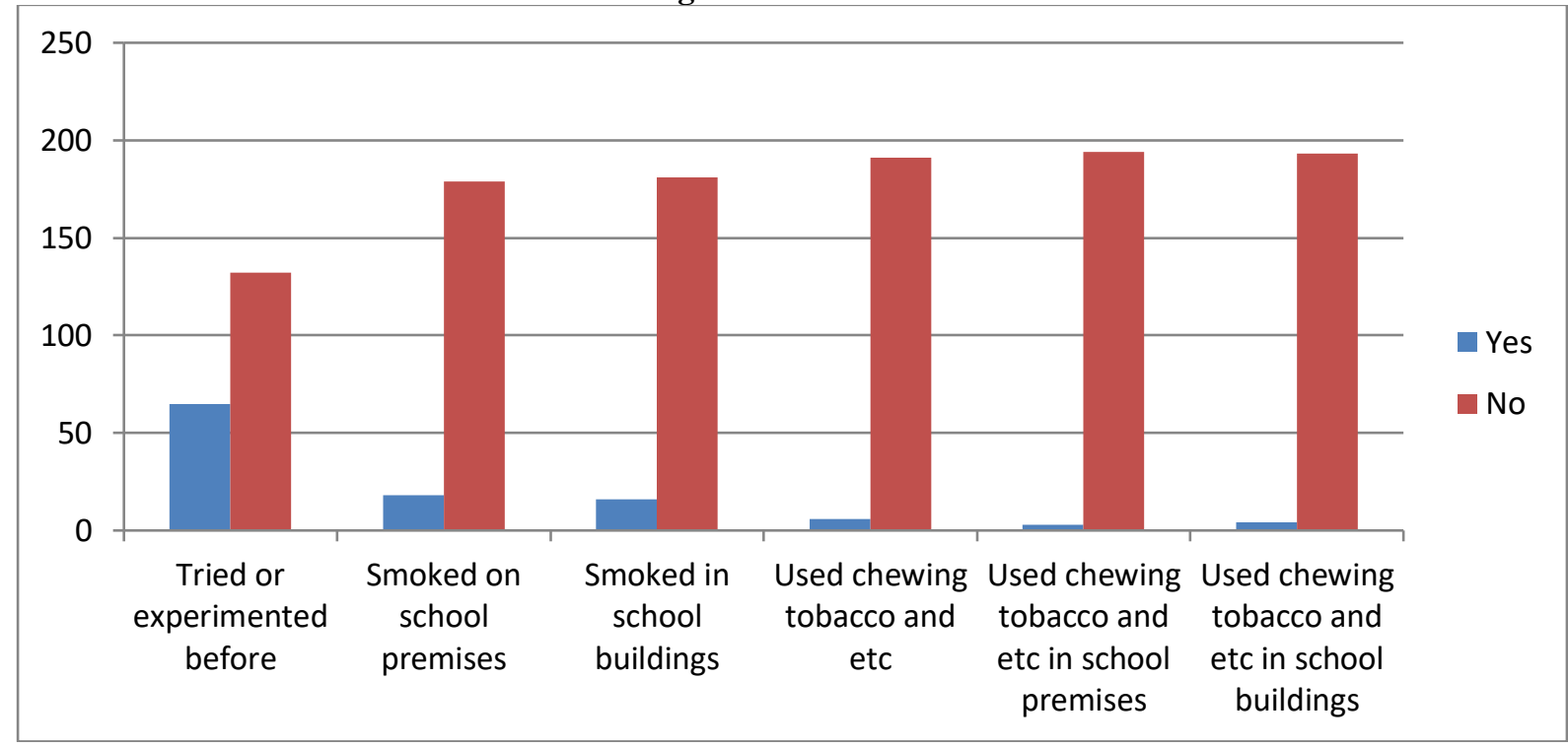

Figure 8 Tried or experimented before

\section{Tried or experimented before}

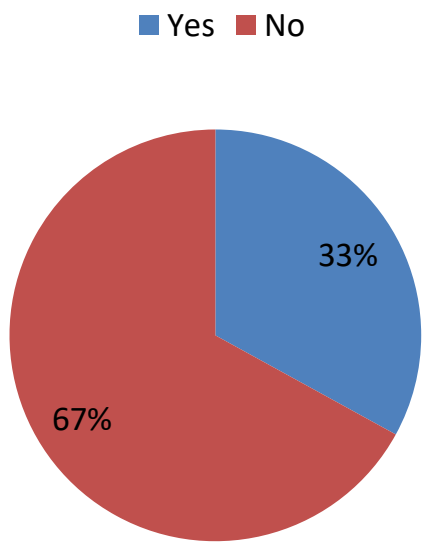


Figure 9 Smoked on school premises

\section{Smoked on school premises}

- Yes No

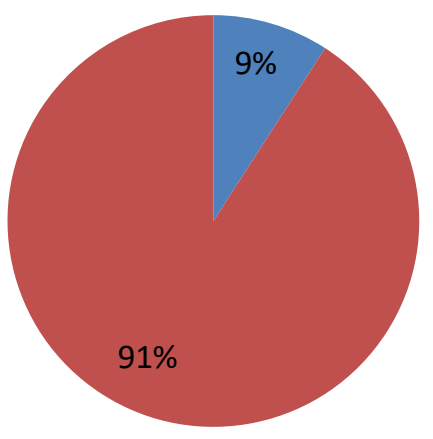

Figure 10 Smoked in school buildings

\section{Smoked in school buildings}

- Yes No

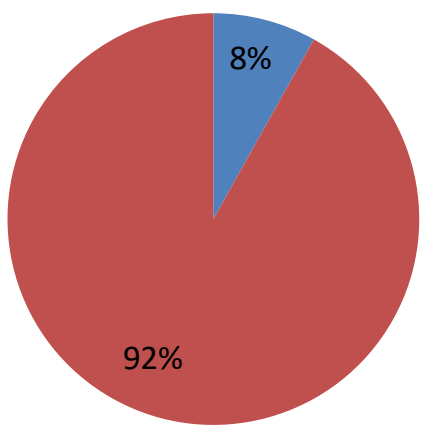


Figure 11 Used chewing tobacco and other tobacco products

\section{Used chewing tobacco and other tobacco products}

$\square$ Yes no

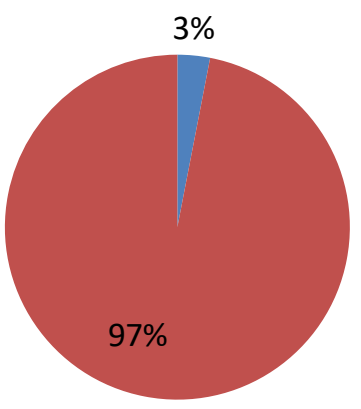

Figure 12 Used chewing tobacco and other tobacco products at school premises

\section{Used chewing tobacco and other tobacco products at school premises}

$$
\text { - Yes No }
$$

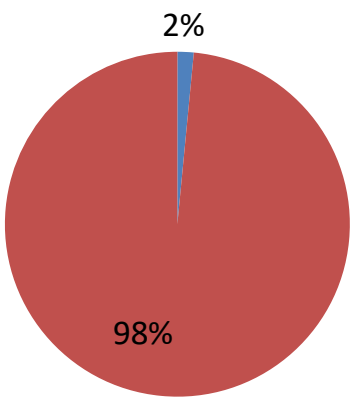


Figure 13 Used chewing tobacco and other tobacco products in school buildings

\section{Used chewing tobacco and other tobacco products in school buildings}

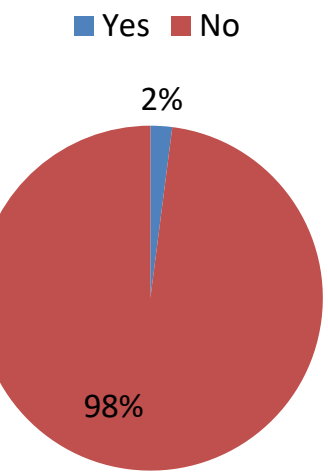

Figure 14 Exposure

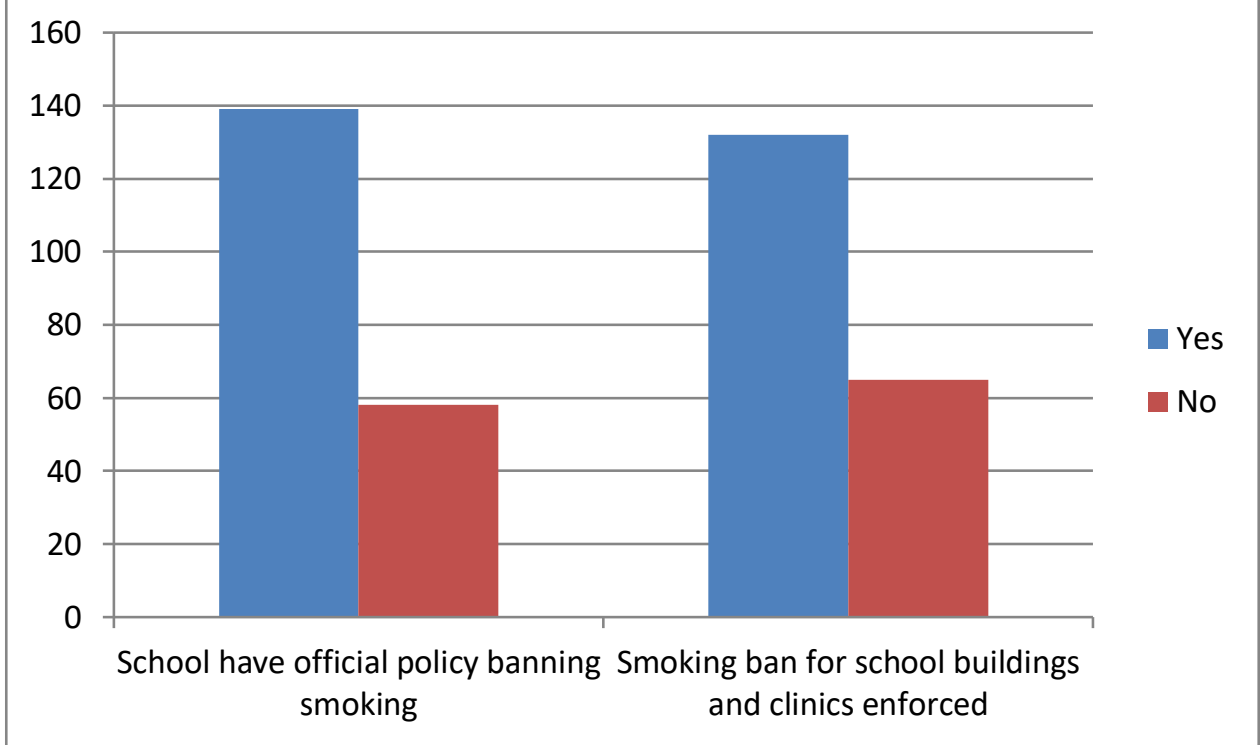


Figure 15 School have official policy banning smoking

\section{School have official policy banning smoking}

$\square$ Yes No

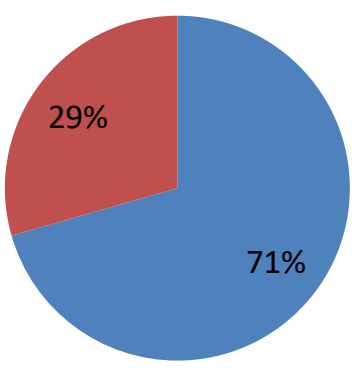

Figure 16 Smoking ban for school buildings and clinics enforced

\section{Smoking ban for school buildings and clinics enforced}

$\square$ Yes No

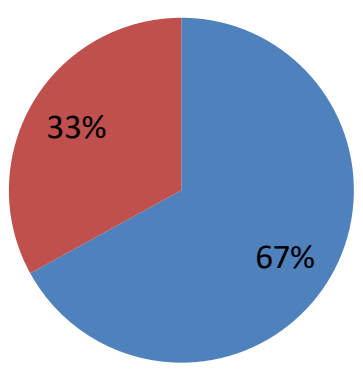




\section{Attitudes}

Figure 17 Attitudes

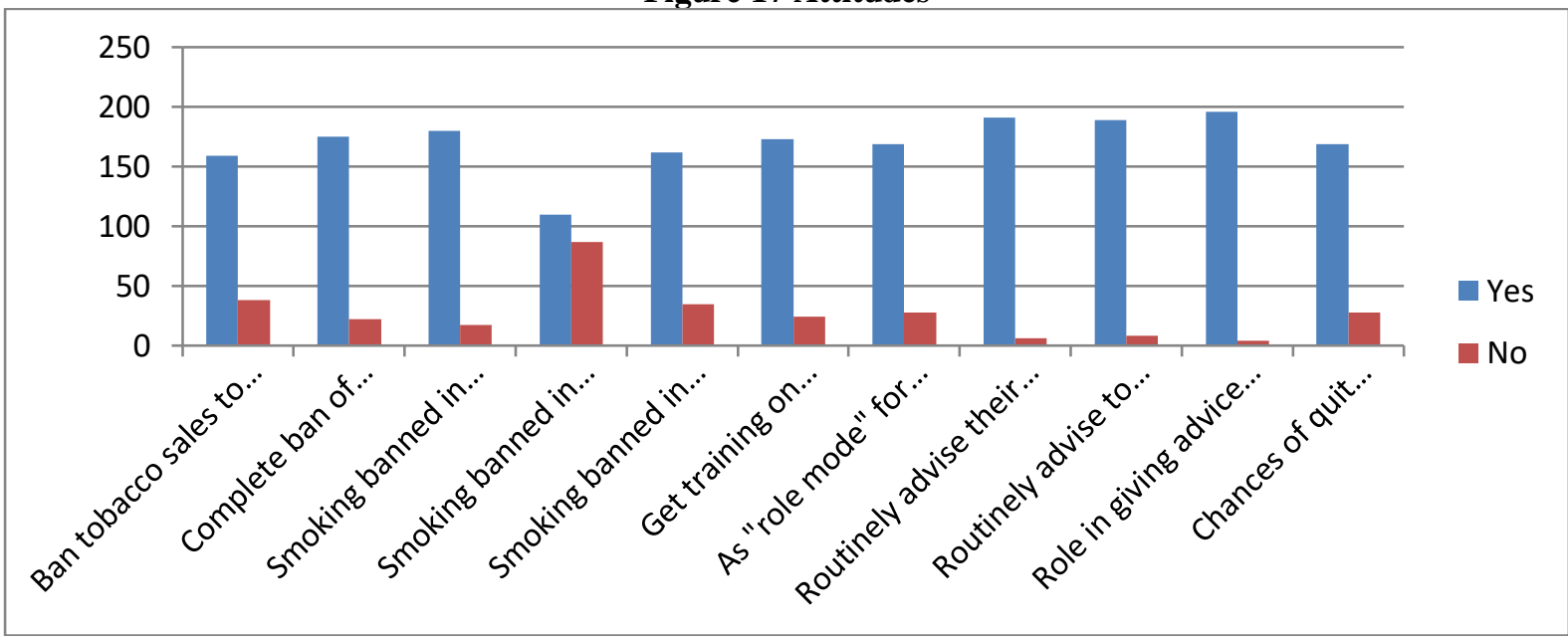

Figure 18 Ban tobacco sales to adolescent

\section{Ban tobacco sales to adolescent}

- Yes $\square$ No

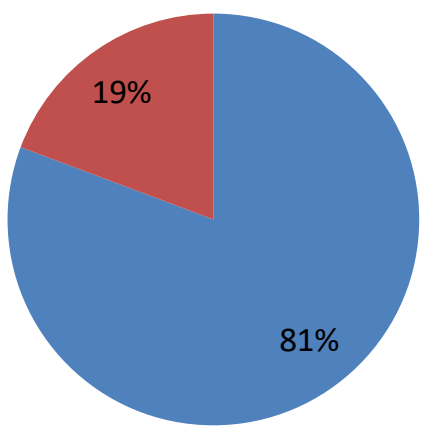


Figure 19 Complete ban of tobacco product advertisement

\section{Complete ban of tobacco product advertisement}

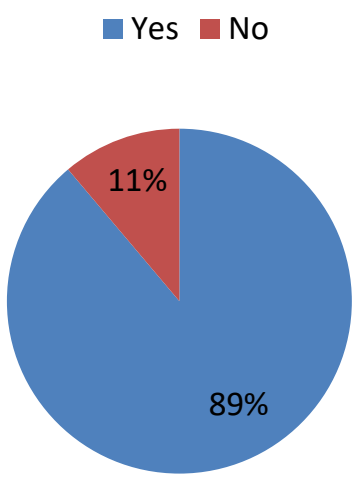

Figure 20 Smoking ban in restaurant

\section{Smoking banned in restaurant}

- Yes No

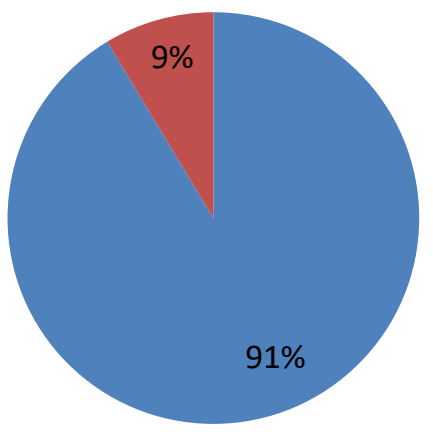


Figure 21 Smoking banned in discos/bars/pubs

\section{Smoking banned in discos/bars/pubs}

- Yes No

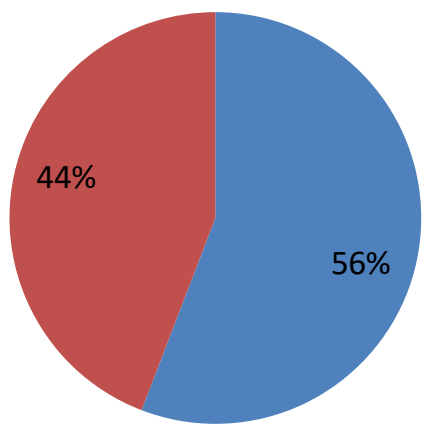

Figure 22 Smoking banned in enclosed public places

\section{Smoking banned in enclosed public} places

$\square$ Yes $\square$ No

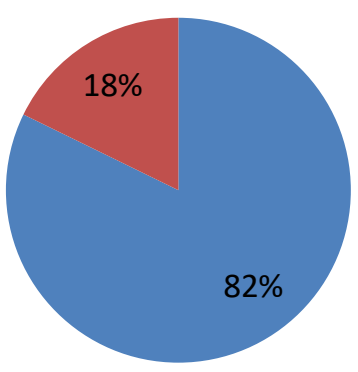


Figure 23 Get training on cessation techniques

\section{Get training on cessation techniques}

- Yes No

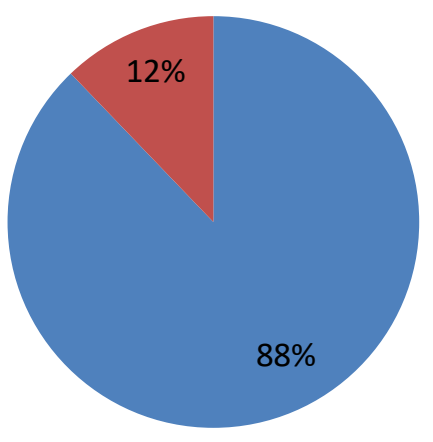

Figure 24 As role model for their patients

\section{As role model for their patients}

- Yes $\square$ No

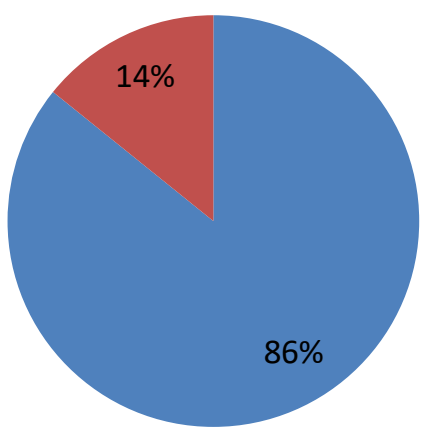


Figure 25 Routinely advise their patients to quit smoking

\section{Routinely advise their patients to quit smoking}

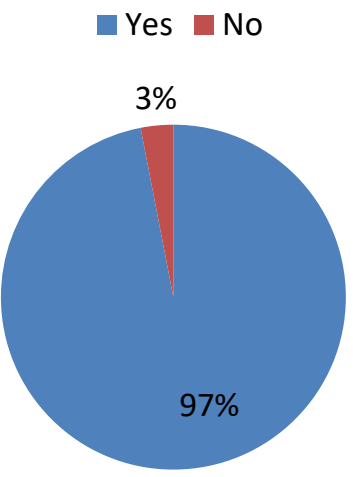

Figure 26 Routinely advise to quit tobacco products

\section{Routinely advise to quit tobacco products}

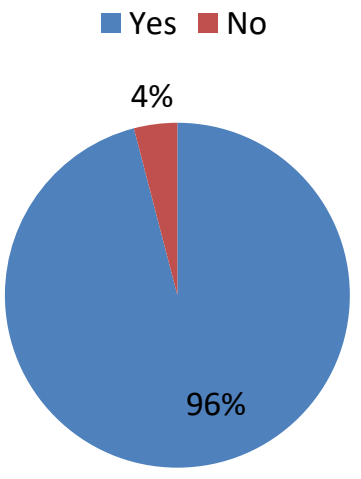


Figure 27 Role in giving advice and information on smoking cessation

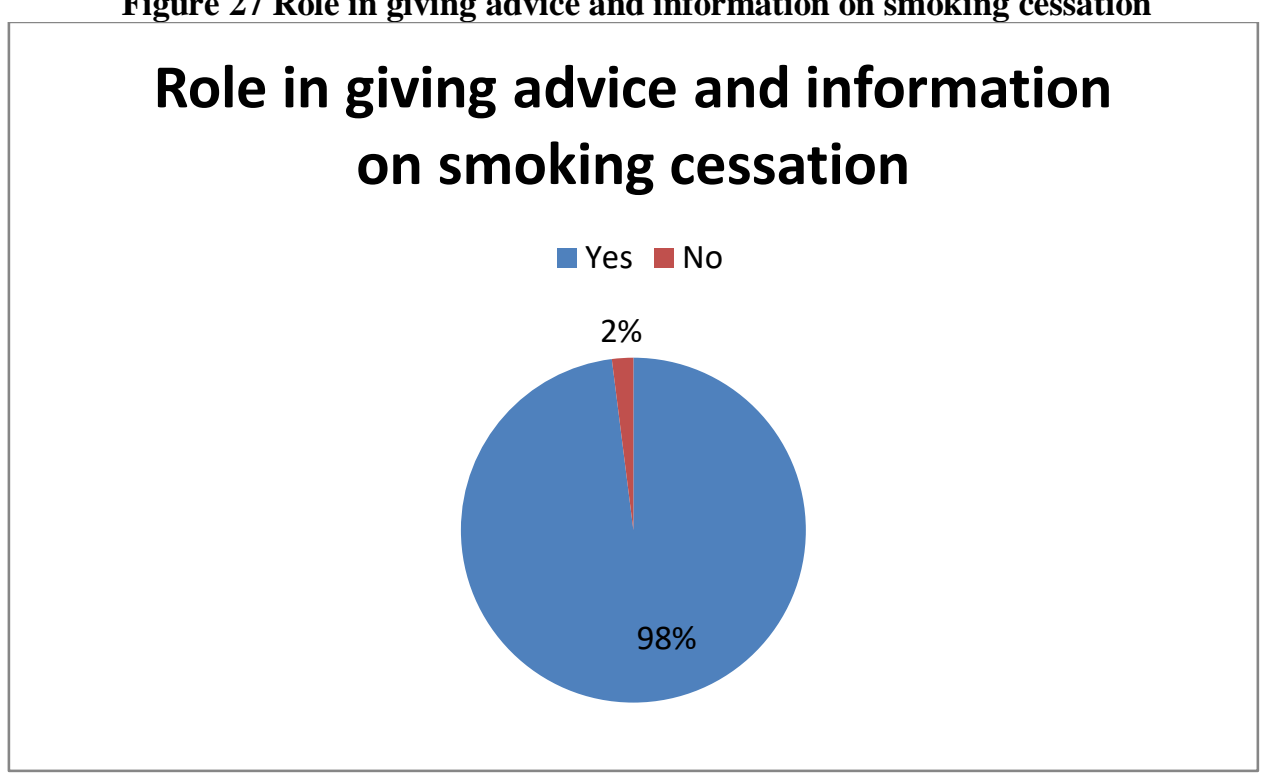

Figure 28 Chances of quit smoking increased if health professionals advise

\section{Chances of quit smoking increased if health professionals advise}

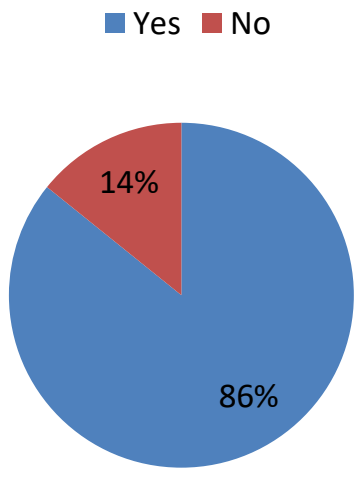




\section{Behaviour /Cessation}

Figure 29 Behaviour/ Cessation

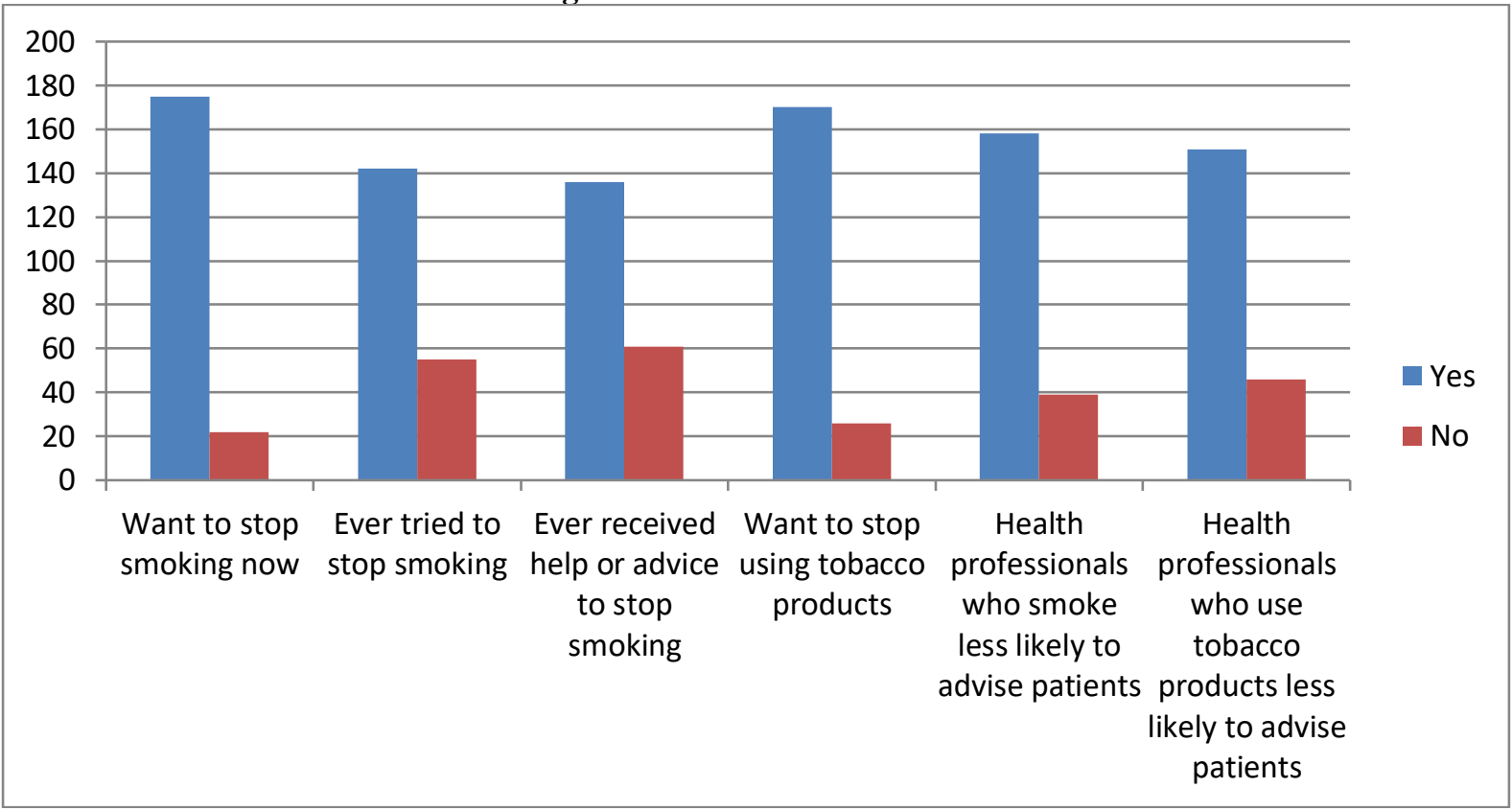

Figure 30 Want to stop smoking now

\section{Want to stop smoking now}

-Yes no

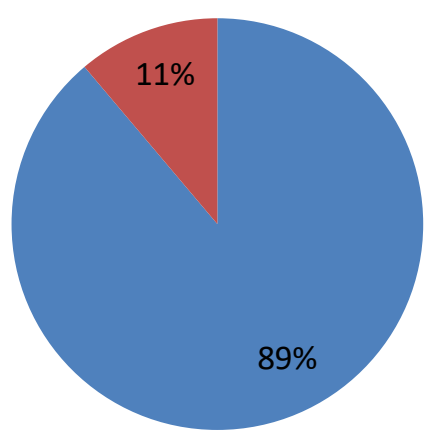


Figure 31 Ever tried to stop smoking

\section{Ever tried to stop smoking}

$\square$ Yes No

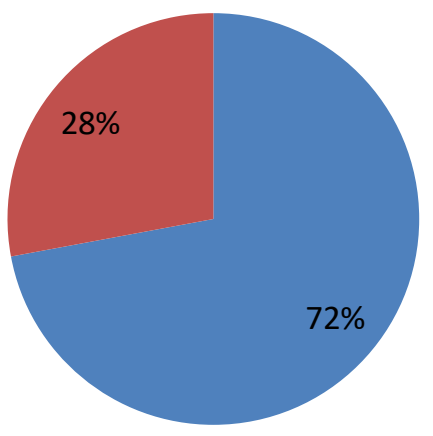

Figure 32 Ever received help or advice to stop smoking

Ever received help or advice to stop smoking

$\square$ Yes $\square$ No

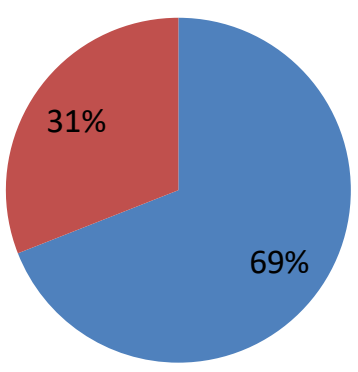


Figure 33 Want to stop using tobacco products

\section{Want to stop using tobacco products}

- Yes no

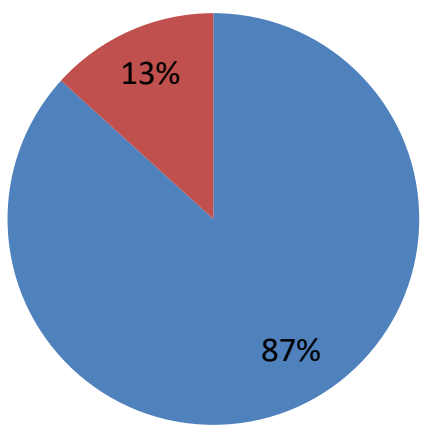

Figure 34 Health Professionals who smoke less likely to advise patients

\section{Health professionals who smoke less} likely to advise patients

$\square$ Yes No

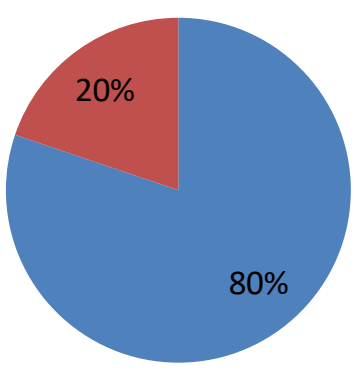


Figure 35 Health professionals who use tobacco products less likely to advice patients

\section{Health professionals who use tobacco products less likely to advice patients}

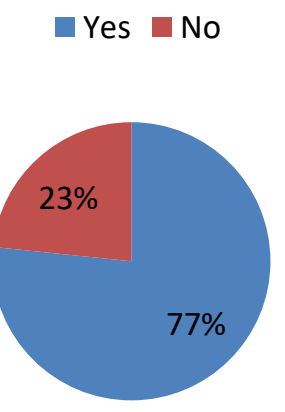

\section{Curriculum/ Training}

Figure 36 Curriculum/ Training

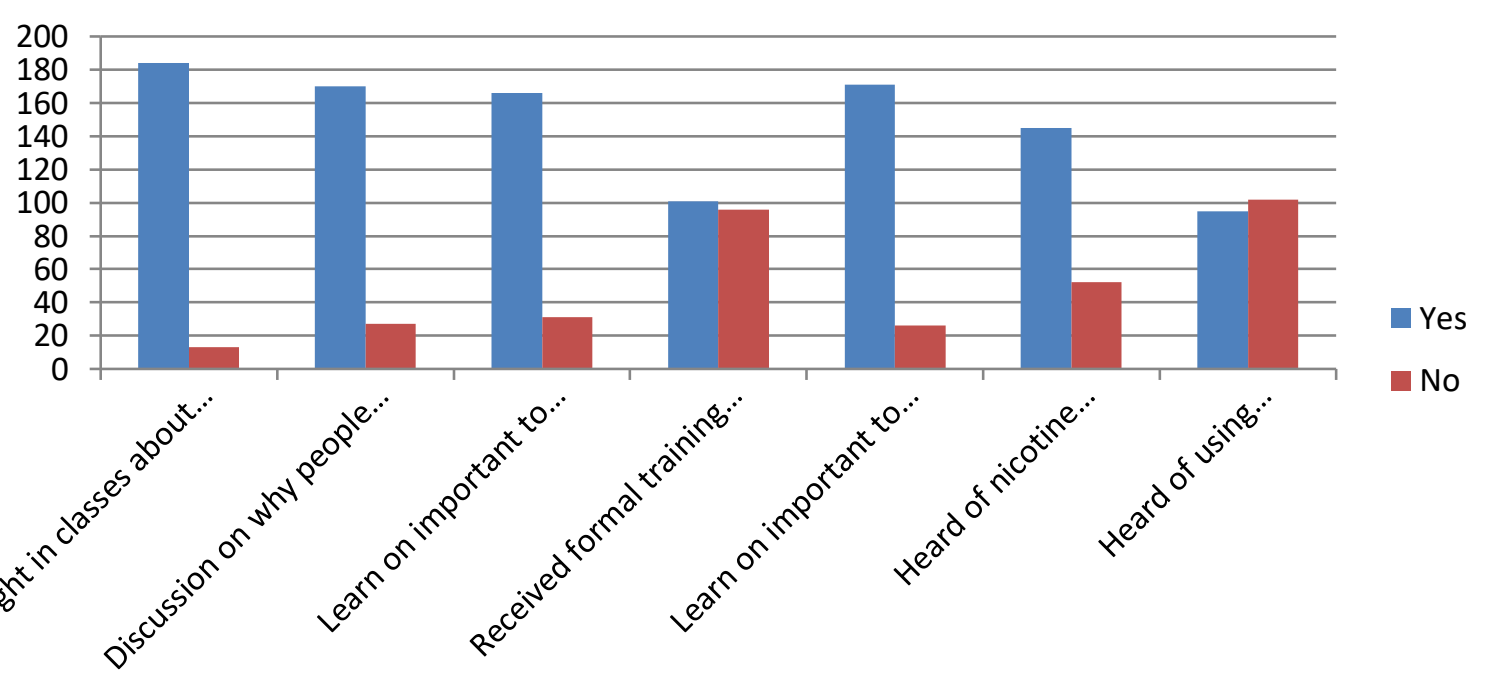


Figure 37 Taught in classes about danger of smoking

\section{Taught in classes about danger of smoking}

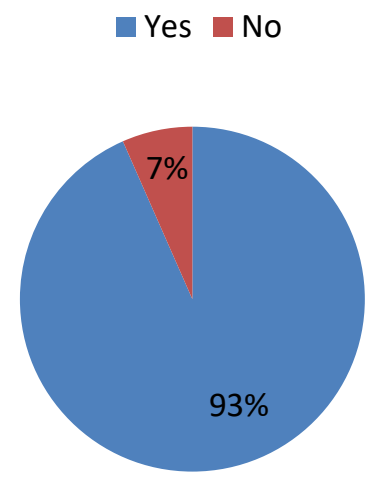

Figure 38 Discussion on why people smoke during school training

\section{Discussion on why people smoke during school training}

$\square$ Yes No

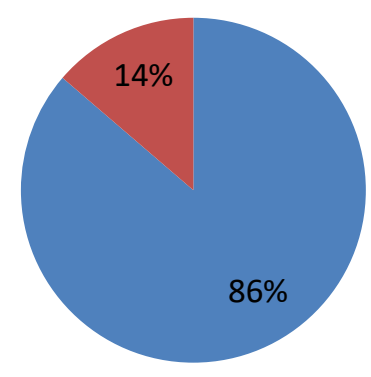


Figure 39 Learn on important to record tobacco history

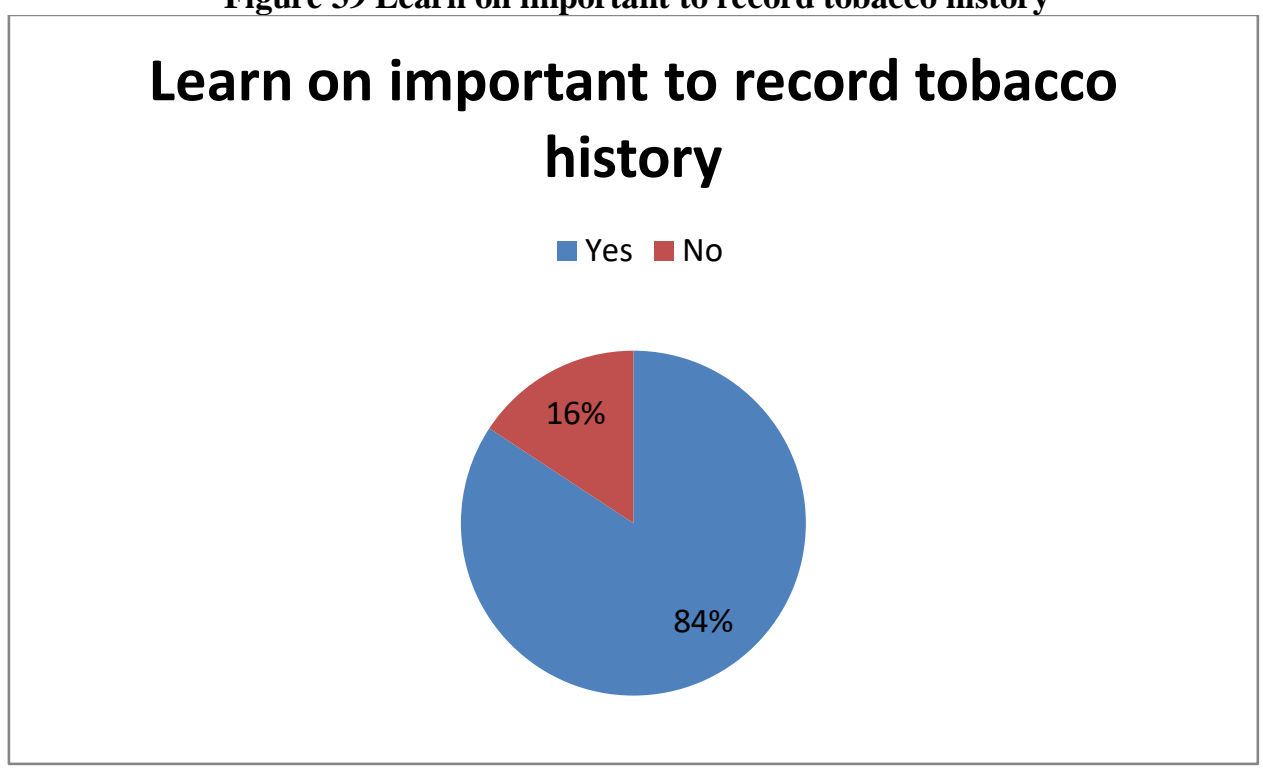

Figure 40 Received formal training in smoking cessation

\section{Received formal training in smoking cessation}

$\square$ Yes No

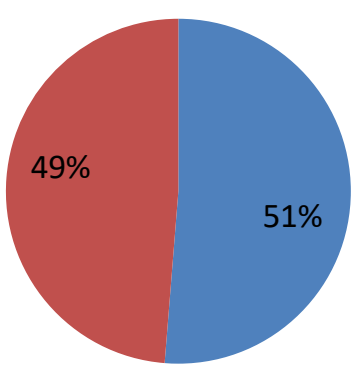


Figure 41 Learn on important to provide educational materials

\section{Learn on important to provide educational materials}

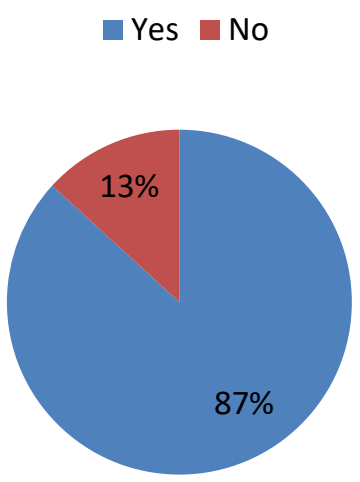

Figure 42 Heard on nicotine replacement therapies in tobacco cessation

\section{Heard on nicotine replacement} therapies in tobacco cessation

$\square$ Yes No

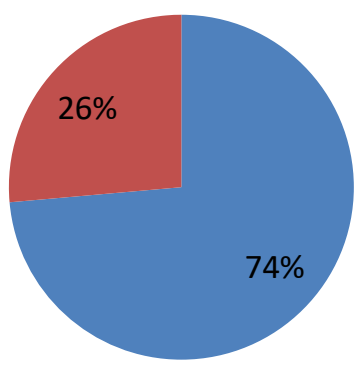


Figure 43 Heard of using antidepressant in tobacco cessation

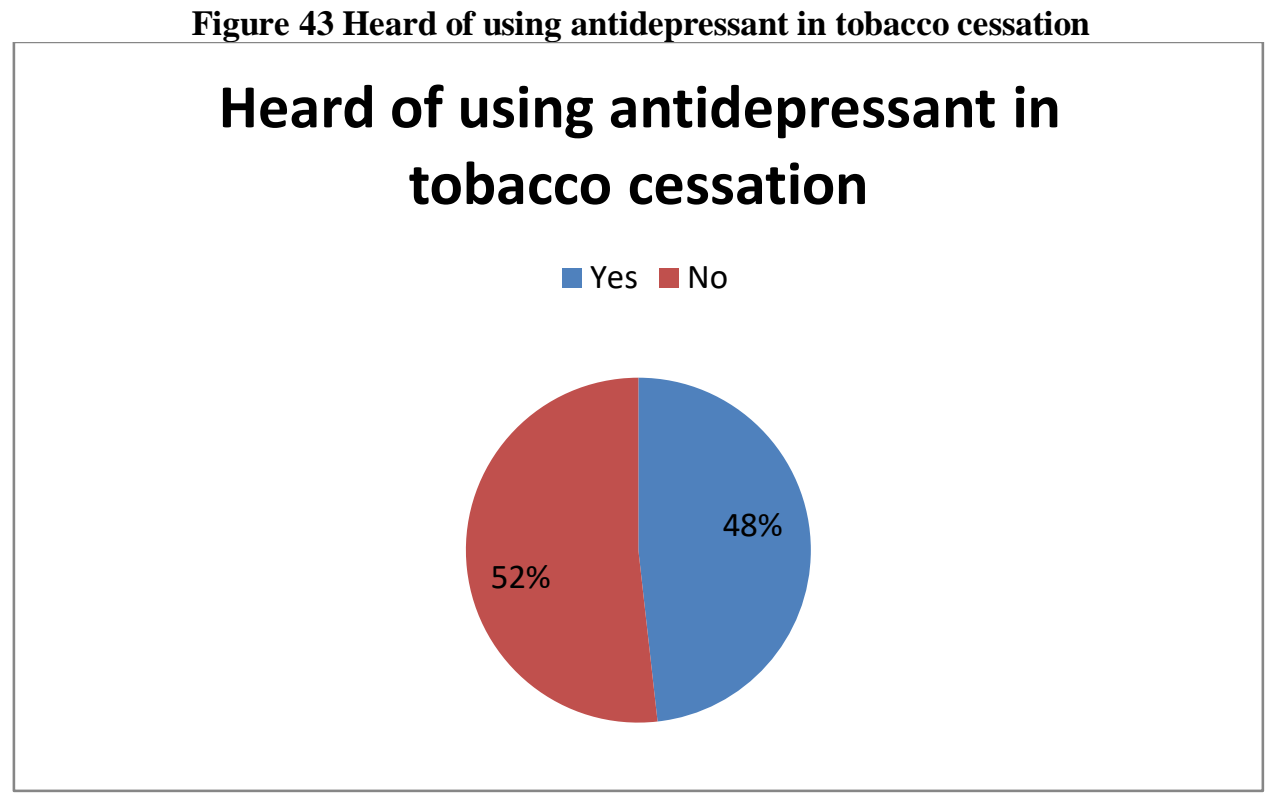

Result:-

Figure 44 Result

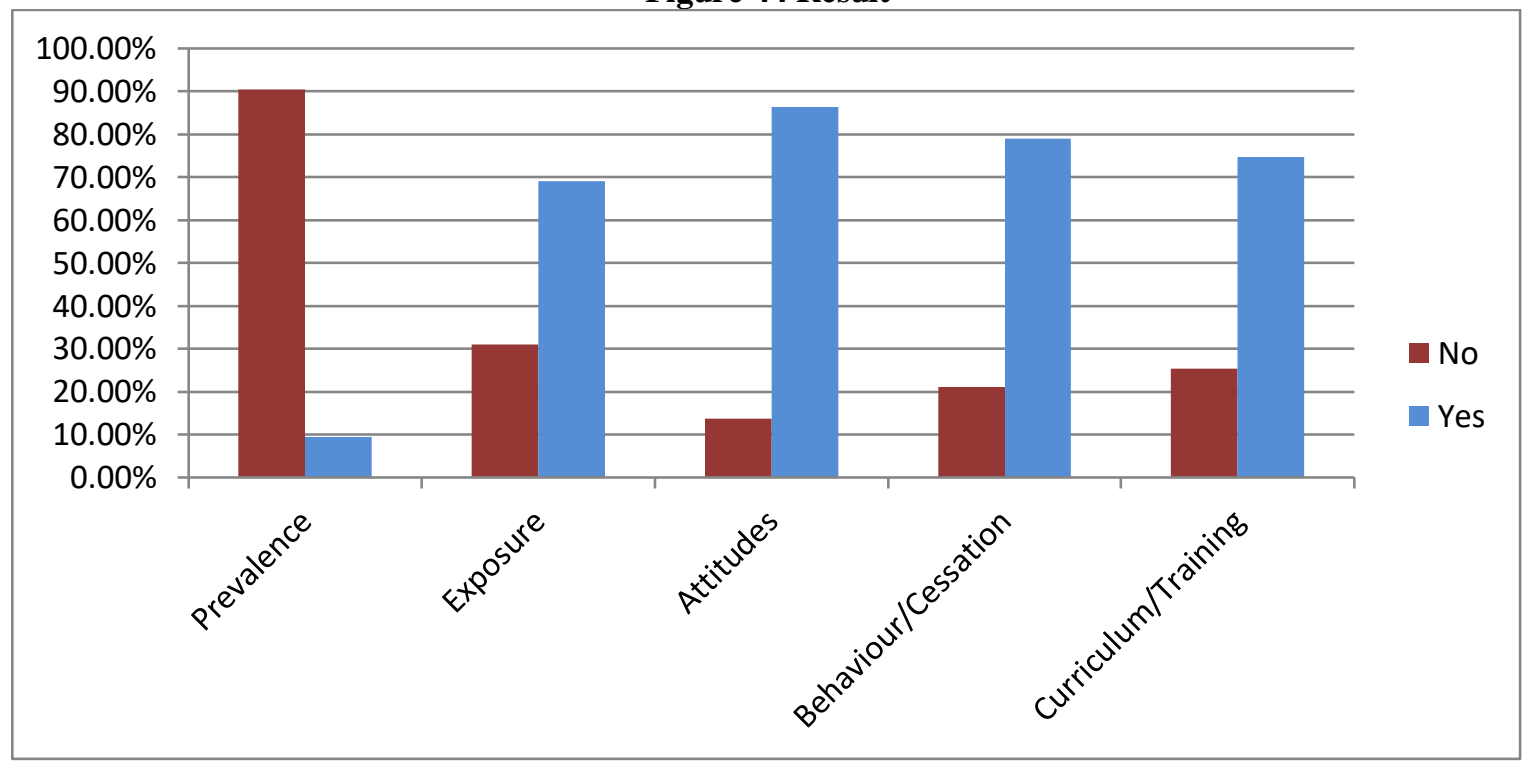

Acknowledgement:

I would like to thank the student subjects who participated from different discipline of the Asia metropolitan university in this project, management of AMU, Co-supervisor who took their fulleffort to acheive this successful result.

\section{References:}

1. Smith SS, Beckley T, Fiore MC (2005). Health care provider use of guideline-based smoking cessation interventions: results from the 2003 Wisconsin Tobacco Survey WMJ 2005; 140:28-31.

2. Fiore C, Jaen CR, Baker TB, Bailey WC, Benowitz NL, Curry SJ, et.al (2008). Treating Tobacco Use and Dependence: 2008 Update. Clinical Practice Guideline. Rockville, MD: US Department of Health and Human Services, Public Health Services. 
3. Davis RM, Wakefield M, Amos A, Gupta PC (2007). The Hitchhiker's Guide to Tobacco Control: A global assessment of harms, remedies, and controversies. Annu Rev Public Health 2007;28:171-94

4. Ussher M, Chambers M, Adams R, Croghan E, Murray R (2011). Evaluation of a nationally disseminated self-help intervention for smoking cessation."Quit Kit". Tob Control 2011;20(5):3802.DOI :10.1136/TC.2010.

5. Ficarra, Gualano et.al (2010). Tobacco use prevalence, knowledge and attitudes among Italian hospital healthcare professionals. The European Journal of Public Health 1-6.March 10, 2010. DOI :10.1093/eurpub/ckq017

6. Bianca Kusma, David Kuarco et al (2010). Berlin's medical students' smoking habits, knowledge about smoking and attitudes toward smoking cessation counselling.Journal of Occupational Medicine and Toxicology 2010,5:9

7. Margherita Ferrante, Caterina Ledda, Roberto Fallico et.al (2013). Prevalence of smoking habits, attitudes, knowledge and beliefs among Health Professional School students.Ann Ist Super Sanita 2013,Vol.49,No.2:143-149.DOI :10.4415/ANN_13_02_06

8. Vijayalakshmi Porredi, Ramachandra et al (2015) : Under graduate nursing student's knowledge, attitudes and perceptions of health professionals' role related to tobacco control and cessation.International Journal of Advanced Medical and Health Research.Volume 2.Issue 1.JanJun 2015

9. Ficarra MG, Gualano MR, Capizzi S, Siliquini R, Liguori G, Manzoli L, et al (2011). Tobacco use prevalence, knowledge and attitudes among Italian hospital healthcare professionals. Eur J Public Health 2011;21:29-34

10. Maria Rosaria Gualano, Claudio Bontempi, Rosella Saulle (2011):Validation of Global Health Professions Student Survey questionnaire in Italy.Italian Journal of Public Health,Year 9,Volume8, Number 4, 2011

11. Warren, C.W.,Sinha, D.N.,Lee,J., V.,\&Jones, N.R..(2009). Tobacco use,exposure to secondhand smoke, and training on cessation counselling among nursing students : crosscountry data from the global health professions student survey (GHPSS), 2005-2009. International Journal of Environmental Research and Public Health, 6, 2534-2549.

12. Cauchi, D.,\&Mamo, J.(2012).Smoking health professional student : an attitudinal challenge for health promotion? International Journal of Environemental Research and Public Health, 9(12), 2550-2561

13. Pericas, J.,Gonzales, S.,Bennasar, M., Pedro, J.D.,Aguilo, A.,\&Bauza, L.(2009).Cognitive dissonance towards smoking habit among nursing and physiotherapy students at the university of Balearic islands in spain. International nursing review, 56(1), 95-101. Retrieved April 24,2013

14. Saddicha S, Rekha DP, Patil BK Murthy P, Benegal v, Isaac MK (2010). Knowledge, Attitude and practices of Indian dental surgeons towards tobacco control : Advances towards prevention.Asian Pac J Cancer Prev 2010;11:939-42

15. Sun, M.C.,Burhoo, P.,Moussa.B.,\&Ramasawmy, D.(2013). Imperative training need of health professionals for improved smoking cessation services. American International Journal of Research in Science, Technology, Engineering\&Mathematics,2(2),240-244.

16. Goniewicz, M.L.,Lingas,E.O.,Hajek,P.(2013).Patterns of electronic cigarette use and user beliefs about their safety and benefits : An Internet survey. Drug and Alcohol Review,32(2),133140. 
17. Chatkin J, Chatkin G. (2009). Learning about smoking during medical school: are we still missing opportunities? Int J Tuberc Lung Dis 2009;13:429-37

18. GTSS Collaborative Group.Tobacco use and cessation counselling (2006): Global Health Professionals Survey Pilot Study, 10 countries, 2005. Tob control 2006;15(Suppl.2):ii31-4,DOI $: 10.1136 /$ TC.2006.015701

19. La Torre G, Kirch W, Bes-Rastrollo M, et al (2012).GHPSS Collaborative Group Tobacco use among medical, students in Europe.Results of a multicentre study using the Global Health Professions Student Survey. Public Health 2012;126:159-64.DOI:10.1016/j.puhe.2011.10.009

20. Yousef A.Al-Turki,DPHC,ABFM (2006).Smoking habits among medical students in Central Saudi Arabia.Saudi Med J 2006;Vol.27(5):700-703

21. Abu S Abdullah, Feng Sing Ming et al (2011). A review of tobacco smoking and smoking cessation practices among physicians in China :1987-2010.Tobacco Control.DOI:10.1136/tobacco control_2011_050135

22. Daniel Fernandez,Antonnio Mollina,Vicente Martin et al (2013).Effectiveness of a course in the control of tobacco use for university health students.Open Journal of Nursing,2013,3,351-357

23. Shalini Singh, Suman Kumar Sinha, Rashmita Saha et al (2014).Knowledge, Attitude and Practice related to tobacco use and its cessation among young medical professionals.Indian journal of Social Psychiatry, 2014,30(1-2),35-42

24. Sarna, L.,\&Bialous, S.A. (2012). A review of images of nurses and smoking on the World Wide Web.Nursing Outlook, 60(5),S36-S46

25. Sarna, L., Bialous, S.A., Nandy,K.,Antonio,A.L.,Yang,Q.(2014). Changes in smoking prevalences among healthcare professionals from 2003 to 2010-2011. The Journal of the American Medical Association, 311(2), 197

26. Berkelmans, A, Burton,D.,Page, K.,\&Worrall-Carter, L.(2011). Registered Nurses' smoking behaviors and their attitudes to personal cessation. Journal of Advance Nursing, 67(7), 15801590.Retrieved April24, 2013

27. Radsma, J.,\& Bottorf,J.(2009) Counteracting ambivalence : nurses who smoke and their health promotion role with patients who smoke. Research in Nursing and Health, 32(4),443-452. Retrieved April 24, 2013

28. Centers for Disease Control and Prevention (n.d) Global tobacco surveillance system data (GTSSData) (2014): global health professions student survey (GHPSS)-overview.(n.d).CDC. Retrieved April 21,2014

29. Kimberly Louise Hebeler.(2009) Smoking habits of healthcare professionals and students and the impact of smoking bans at an academic medical center in Northwest Ohio. Master's and Doctoral Projects.Paper 329

30. WHO - Report on the global tobacco epidemic (2008). Available at: http://www.who.int/tobacco/mpower/mpower_report_full_2008.pdf

31. 040535Walton, A.(2013, March 28) (2013). Should companies have the right to refuse to hire smokers?- Forbes. Information for the World's Business Leaders- Forbes.com. Retrieved April 25, 2013, from http://www.forbes.com/sites/alicegwalton/2013/03/28 should-companies-have-theright-to-refuse-to-hire-smokers/

32. World Health Organization: Five years of progress in global tobacco control, (2013). In WHO report on the global tobacco epidemic 2013: enforcing bans on tobacco advertising, 
promotion and sponsorship. Retrieved March 17, 2014,from

http://www.who.int/tobacco/globalreport/2013/achievement.pdf?ua=1

33. World Health Organization: Achievement continues but much work remain (2013). In WHO report on the global tobacco epidemic 2013 : enforcing bans on tobacco advertising, promotion and sponsorship. Retrieved March 17,2014,from

http://www. who.int/tobacco/globalreport/2013/achievement.pdf?ua=1 